\title{
THE PRACTICE OF SURGERY IN LEEDS 1823-1824
}

\author{
by
}

\section{S. T. ANNING*}

THIS PAPER is based on a leather-bound manuscript notebook found in the cellars of the Leeds Medical School a few years ago. It commences on 20 March 1823. No author's name is given but it would seem to be the notes of an apothecary. As Richard Farrer of Leeds was assistant apothecary at the General Infirmary at Leeds from March 1823 to July 1825, it seems probable that he wrote it. Farrer became locum apothecary from November 1824 for an uncertain period (while J. C. Cooper attended lectures in London) and apothecary from June 1826 to August 1829 when he resigned on account of illness. He qualified M.R.C.S. Eng., and L.S.A. in 1826. ${ }^{1}$

The General Infirmary at Leeds had been founded in 1767 and was the only hospital in the town. Leeds was a prosperous place, being a centre for the wool and cloth trade, and the market for the products of spinning, dyeing, and weaving carried on in the outlying hill towns. This profitable trade came to Leeds because the river Aire had been made navigable to the town just before the close of the seventeenth century, and seventy years later was joined by a cut to the Ouse at Selby whence merchandise could be sent on to Hull for export. There were also flax spinning, dyeing, leather tanning and shoe-making, silk spinning and weaving, coal mining, engineering and iron foundries, and the manufacture of pottery and glass. As a result, the population of Leeds and its inner parishes increased from about 17,000 in 1775 to 82,000 in 1838 .

However, the population served by the General Infirmary cannot be readily estimated. The notebook gives the place of origin of each patient (see Appendix I) and it will be seen that many came from outlying parts.

Three surgeons are mentioned in the notebook: Thomas Chorley (dates of birth and death uncertain), surgeon to the Infirmary 1794 to 1833; William Hey the second (1772-1844), surgeon 1812 to 1830; and Samuel Smith (1790-1867), surgeon 1819 to 1864. It should be mentioned here that one of the rules of the Infirmary, laid down in 1767 and still in force in 1823, stated: "That no Amputation or other great Operation, except an urgent Occasion require it, be performed, without a previous Consultation of the Physicians and Surgeons; and no one shall be admitted to see the Practice of the House without their Consent."2

The notebook consists of four sections: first, a list of operations carried out between March 1823 and August 1824 which is shown in Appendix II and is, judging *S. T. Anning, M.A., M.D., F.R.C.P., 61a Weetwood Lane, Leeds LS16 5NP.

'S. T. Anning, 'The apothecaries of the General Infirmary at Leeds', Med. Hist., 1961, 5: 221-238.

2 S. T. Anning, The General Infirmary at Leeds, 2 vols., Edinburgh, Livingstone, 1963-66, vol. 1, p. 33. 


\section{S. T. Anning}

from the fourth section, not complete; second, a list of accidents shown in Appendix III; third, details of fifty-six patients suffering from accidents: and last, "brief notes of some Cases after Operation".

BRIEF NOTES OF THE TREATMENT OF SOME PARTICULAR ACCIDENTS

It would be tedious to recount in full the details described in this section, so only a summary of each case is given.

Case 1. I. H. male aged 18. Injury of fingers on 19 April 1823. "In this case the Fingers except the Index were much fractured \& lacerated so as to require removal by the Meta Carpal Bones ... the Index Finger . . . sloughed away in a few days." The hand was elevated and a "double Poultice of Bread" applied. Three or four abscesses formed which were opened. Further sloughing but "the Case went on afterwards in a favourable \& usual Way". Possibly an accident from machinery.

Case 2. J. P. male aged 11. Compound fracture of both legs on 31 May 1823. "Happened by a Cart running passing over both Legs-was a large Wound on fore part of left Leg through which both the Tibia \& Fibula protruded to about $\frac{1}{2}$ in.: these were sawn off-simple dressings applied." Much contusion. Patient bled. Emplastrum Saponis applied. Splints and straps. Purgatives. The patient became delirious and died on 8 June 1823.

Case 3. A. M. female aged 16. Compound fracture left leg on 7 June 1823. “. . limb was laid in a double Oatmeal Poultice in a bent position for 17 days, by this time the Swelling \& Inflamation which had not been very violent almost altogether subsidedthe Limb was then gently extended \& put upon the Eel [Heel]." Splints and straps applied and limb put into a "Fracture Box". Discharging sores were almost healed by 31 July. Out of bed 12 days later. Leg "nearly straight". Discharged 8 August. On 3 September, "Leg still crooked", and she walked with a little limp.

Case 4. J. B. male aged 30. Compound fracture of thigh. "This accident happened in consequence of a large heavy piece of timber falling upon the Man's Thigh". Fracture a little above the knee. Much swelling and a deep wound. Lotio Frigida applied [liq. ammon. acet. in spirit ${ }^{3}$ ]. Poultices. Limb elevated with pillows. Abscesses formed and were drained. Retention of urine-catheterization. Patient died on 10 August 1823.

Case 5. J. B. male aged 39. Dislocated right shoulder on 4 July 1823. "This patient came to the Infirmary with the above Accident which happened in the Act of striking violently a Cow with a Stick \& before the Stick had actually reached the Cow-a powerful \& muscular Man in good robust health-head of the Humerus lodged under Pectoral Muscle- to be felt by digging the Fingers deeply into the Muscle." Reduction accomplished very easily by Mr. Hey and two assistants. Details given.

'S. T. Anning, 'A hospital pharmacopoeia of the nineteenth century', Med. Hist., 1966, 10: 70-75. 


\section{The practice of surgery in Leeds 1823-1824}

Case 6. M. R. male aged 23. Concussion of brain etc. ". . . was brought into the Infirmary in a State of Insensibility abt. 3 o'Clock in the Afternoon of Wednesday July 10-had been buried in a Sewer path falling in of Earth for the Space of 3 or 4 Minutes-so that during this time Respiration was suspended." [Public sewers were not built in Leeds until 1850-53 but private sewers were built earlier, draining into the river Aire.] Wine and water given and venesection carried out. He recovered consciousness in about twelve hours and was discharged two days later.

Case 7. "Another Poor Man abt. 60 yrs was burried [sic] in the Sewer with the Abovehe came into the Infirmary with nearly the same Symptoms, only in a more aggravated form-he suffered Fracture of the Sternum \& Lower Jaw, with Emphysema of the Chest Abdomen \& Arm-he lingered in a state of insensibility till 7 o'Clock next Morg. when he died." Several punctures were made to evacuate the pent-up air.

Case 8. E. P. female aged 33. "Fungus Haematodes. Came into Infirmary with Fungus Haematodes of Calf of left Leg-had under several Medl. Men for some weeks back and on the 11th. a puncture was made into Tumor which discharged a little blood mixed with whitish Clots. Swelling was strapped tightly up with Emp. Adhaesiv.- -when she came in the limb was much swollen \& an erysipelas was spreading upwards \& Threatening to terminate in Gangrene-indeed there was a gangrenous vesicle immediately surrounding the Wound-the Inflamation [sic] continued extending up Thigh to Hip-speedily terminated in Mortification-Patient in a most emaciated State \& had a low kind of Fever - there was a constant oozing of extremely foetid bloody Matter from the Wound-Was abt. $4 \frac{1}{2} \mathrm{~m}$. gone with Chd. \& near 6 o'Clock A.M. [next day] had a sudden \& unexpected gush of Waters from the Uterus, almost without any pain she parted with a dead foetus footling-Placenta followed soon after. . . . a Consultation was held at 9 o'Clock next Morng. (14 day) but she then was fast sinking and died abt. 12 o'Clock." It may be assumed that the condition at first was venous thrombosis.

Case 9. J. L. male aged 60 admitted at 1 p.m. on 15 May with retention of urine. ". . . subject to retention of Urine from spasm which required nothing but a single introduction of the Catheter to give relief-in the Night of 13th. had another attack, and abt. 9 o'Clock next Morning 14th. a Surgeon introduced the Catheter \& evacuated the Bladder from his unskilfulness in the Operation he did it with great difficulty, pain \& at the same time lacerated the Urethra,-the Instrument was withdrawn a quantity of blood instilled from Urethra, the man continud. till abt. same time next Mornig. (9 o'Clock of 15th.) without beeing [sic] able to void Urine (during which interval [24 hours] no means whatever were used for his relief of suffering) at this time ( 9 o'Clock of 15 th.) another Surgeon passed the Catheter with moderate ease $\&$ drew off abt. — of water, tho. somewhat relieved by this he continued to suffer urgently and in this state was brought into Infirmary-Mr. Chorley made several trials to pass Catheter both silver \& Elastic Gum, as Mr. Cooper [the Apothecary] had done previously. 8oz. of blood were then taken from the Arm \& he was immersed into a warm Bath, Enema Purgans \& emolliens were administered, as well as Purga- 


\section{S. T. Anning}

tives by the Mouth. All these means failing a Consultation was called abt. 9 o'Clock fully expecting that the Bladder would have to be punctured. Mr. Chorley again tried and again failed-Mr. C. had the Patient lain on his back in the Middle of the Bed. Mr. Hey then took a thicker elastic Gum Catheter than Mr. C's and having drawn the Patient's Breech to the bottom of the Bed with his legs elevated at right Angles \& himself kneeling down at the Bottom of the Bed directly in front of the Man introduced the Catheter with great ease. Mr. H. repeated the Operation next mornig. after which as he was still unable to micturate the Instrument was allowed to remain in the Bladder the Water taken off occasionally-in 3 or 4 days after the Catheter had been in that Bladder it was through the ignorance of the Nurse withdrawn, but another was passed with much facility." Occasional catheterization continued and he learnt to pass it himself. After being debilitated "from long Confinement to Bed" his strength improved and he was "therefore made O.P.".

Case 10. S. M. male aged 13 admitted for injury of the hand and fingers. "9th. July got his left Hand intangled in Machinery by which the three middle Fingers were severely fractured \& contused that it was deemed necessary to remove them by the Carpal Bones-care being taken to preserve as much as possible of Integument to cover the Wound. The Hand was dressed with Ungt. Cerae [yellow wax and olive oil $^{4}$ ]. Lint in strips applied so as to give all support to the Integument-was then put into a double Poultice of bread which was renewed daily. ..." There was a good deal of infection and a deep abscess above the wrist which was incised but slowly the condition settled. On 1 October he was said to be cured. A note states: "With this Patient the parts returned so much to their natural Size \& Appearance that he could make the little Finger \& Thumb meet so as to take hold of little matters. This will certainly be considerable advantage \& I think very strongly points out the great propriety of preserving as much as possible of the fractured \& contused Fingers."

Case 11. J. B. V. female aged 9 admitted for injury of hand and fingers on 16 July 1823. "This Case like the preceeding [sic] one happened in consequence of Machinery, -all the Fingers except the little one which had suffered Comp. Fracture were so much fractured lacerated so as to require removal by the Carpal Bone,-Care being taken as before to preserve as much as possible of Integument,- - this was dressed as the other Case \& poultices applied,-it was necessary to secure several Arteries which were done with some degree of trouble \& difficulty." There was much sloughing but no inflammation above the wrist. Splints were used to keep the little finger straight. She was made an outpatient on 29 August and on 1 October was described as "cured". "The little Finger, the only one left seemed as if it would grow very useful in lifting etc."

Case 12. G. M. male aged 20 admitted on 3 July with fracture of fibula. No information given regarding the accident. "App. Emp. Saponis in Strips 18 tailed Bandages, limb laid extended upon Pillows covered with a Linen Cloth, with a Splint one each side \& surrounded with 3 Straps. 10th. looked at, in consequence of the further

\footnotetext{
- Ibid.
} 
settling of the swelling, plaisters had become slack and were therefore loosed out \& tightened. 17th. Plaisters be undone \& tightened still more." No further information is given.

Case 13. J. L. male aged 24 admitted on 7 July 1823 with simple fracture of fibula. No details, but "Limb put in short Splints: first Emp. Saponis next Flannel Bandage, then two Splints each abt. 14 inch long lined with Tow applied to either side of Leg over which a Cotton Bandage-30. to get up a little-Box taken away. . . . Augt. 14 Everything removed from Leg \& fresh Plaister applied with circular Cotton Roller \& made O.P.- -allowed to walk as much as could with Comfort \& care."

Case 14. T. K. male aged 20 admitted on 2 July with simple fracture of radius and ulna. No details about accident. "2. App. Catapl. Lin dupl: 4th. Appl. Emp. Saponis in Flannel Bandage next two Splints, \& lastly Calico Bandage-looked at-Emp. tightened, Ulna a little limited, Radius still loose, but straight-19. Looked at again, Emp. be tightened. Radius still united-24. Again looked at. Reapp. Emp: to Radius still quite ununited.-31. looked at again Plaisters renewed. Fractured Radius acquired a considerable degree of firmness since 24th. 7th. Augst. looked at-Radius still more firm-Ulna felt rather more loose. 11th. Both Bones still very loose \& still worked about by Mr. C." No more details.

Case 15. J. F. male aged 21 admitted with simple fracture of thigh. "Fractured Thigh July 18 Accident happened in consequence of some coal falling upon the Limb in the Pitt. . . . 24. Swelling having in a great measure subsided it was put up in the following manner-A Bed with a good firm Matrass [sic] was got ready. 18 tailed Bandages, strips of Emp. Saponis abt. $1 \frac{3}{4}$ or 2 in. broad placed upon the Bandage parallel with its tails, \& the Strip so put as enough to cover a small part of the Preceding one. Surgeon's Tow Straps with Buckles, short Splints about 3 or $3 \frac{1}{2}$ inch broad \& 12 or 14 long, 2 long Splints a yd. or better in Length, \& 6 to 8 inch in Breadth, several cotton pads containing Wool from 8 to 14 or 16 inch long, a Calico Bandage, Two or 3 small feather Pillows 8 or 10 inch square filled with feathers, a Common Feather Pillow covered with a Piece of soft Linen Cloth \& lastly a Traction Box. All preparatory measures being thus arranged, Poultices were removed from Thigh which was well washed with Sponge \& water. Patient was then with the Assistance of 3 or 4 men carried to the new made Bed, put in the middle in as straight a position as possible: then 2 Assistants elevating the limb, one leg, \& another Thigh Mr. C put the Bandage with Plaisters rapidly under the Thigh: he then took hold of the Three \& an Assistant the Leg: the limb was made to descend straight as maybe, at the same time using moderate Extension. Assistant keeps the limb firmly down \& extended while the Surgeon applies Plaister \& Bandages -4 of the short Splints lined with Tow were then applied, one to the Top, one to the underpt. \& one to each side of the Thigh. 3 pieces of Calico Bandage each abt. 1 yard long \& $2 \frac{1}{2}$ or 3 in. long [sic] were next carried at equal distances round these four short Splints, $\&$ pinned firmly. Leg then raised so that a pillow covered with soft Linen Cloth was put underneath. Three of the soft Pads of Wool each abt. the same size of the Splints already 


\section{S. T. Anning}

used (as before mentioned) were now put on, one on each side \& Another at the Top of the Thigh, upon the last or top pad another short Splint was placed, the long Splints one on each side of the limb were now put exterior to all viz to Pads of Thigh \& Pillow of Leg-these were bound on with 3 straps which surrounded the Thigh at like distances, \& the Leg was tied with two Pieces of Calico which answered same thing as Straps on thigh lastly the Limb was put into a Fracture Box, a small square Pillow being first under the Eel [Heel], to give support and another between the Foot $\&$ Box with the same View, and also a Bag containing sand was suspended from the Eel, to keep the limb steady \& in an extended state. ... Augt. 28. All Plaisters removed, limb not much swelled, straight, ... fracture rather diagonal, handled pretty roughly, 3 short Splints applied with Plas. \& 2 Bandages \& made O.P."

Case 16. J. B. male aged 21 admitted on 19 July under Mr. Hey with a severe injury of the right foot. "This Accident happened by a large heavy Stone falling upon the Foot which was in pt. much bruised, lacerated etc. On each side were two deep Wounds both of which extended downwards forewards so that there was not more than 1 or $1 \frac{1}{2}$ in. intervened between them or the hole. Haemorrhage had been considerable. There was a Comp. dislocation of two of the Bones of the Foot-Two or Three Arteries were taken which from the Wounds being deep \& filled with Coagulent [sic] \& the parts being much bruised \& lacerated was a matter of some difficulty, indeed it was found necessary to divide with the Knife the intervening pt. of the Foot before it could be accomplished, this being done Emp. Cerae in Strips were applied \& the Foot put into a double Oatmeal Poultice this dressing \& Poultice were repeated daily-till 29 when Catapl. was discontinued \& Bandages Flannel applied in Loco. Leg was now put in a extended Position upon a Pillow \& enclosed within a Fracture Box." No further details.

Case 17. M. A. B. female aged 18 admitted on June 27 with spasms. "Begun abt. 5 yrs ago with Spasms of right Knee which was drawn backwards, continued so perhaps a few minutes then went off, but returned again in $\mathrm{nr} . \frac{1}{2}$ hour, \& was repeated at such intervals during the whole of one day, \& perhaps night $\&$ after which it did not return of 6 or 8 weeks \& after she began to menstruate, thus spasms were generally more violent at her periods. . . . in other respects pretty well but since Jany. or Feby. her attacks have been much more violent $\&$ frequent-it first comes on quite suddenly (falling insensible in Hysteria) with strong contraction of the right Knee or leg ... has been under the Care of several Medl. Men who have bled purged etc. her but without any Benefit. since she came here has taken a Calomel \& Jalap Bolus ... has head shorned \& Lotio Frigid. applied constantly . . . cupped behind Neck been bled at Jugulars, had 3 blisters Neck \& downwards along Spine ... ." No further details, but the patient seems to have had hysteria.

Case 18. D. D. male aged 6 admitted on 28 July with fractured thigh. No details of accident. Treated similarly to Case 15. Made O.P. 22 August.

Case 19. J. L. male aged 16 admitted on 3 August with fracture of cervix femoris 
"in consequence of getting kicked out a Gig but its upsetting,--just above the Trochanter Mag. - a considerable Swelling but little or no Contusion or inflamation [sic]. Patient laid completely flat on his back both Legs (Limb whole) were elevated with Feet upon Bed-thus Hip, Knee \& Foot forming a triangle. The Surgeon then taking hold of the Thigh \& an assistant the Leg \& elevating them, an Inclined Plane (traction used on such occasions) was applied by another on the Bed with its upper extremity reaching the Tuberosity of Os Trochii-Surgeon extending thigh made it to descend upon Plane (on one side it) \& leg on the other at abt. the Angle thus marked $\Delta$. 18 tailed Bandages covered with Straps of Emp. Sap. was put between thigh \& Plane, \& applied tightly to the Limb by Surgeon-assistant holding it steady \& rather on the Stretch,-next 3 Splints abt. 4 or $4 \frac{3}{4}$ in: brd. \& 18 or 16 long lined with treble Flannel were made of - one to each \& the other to top of Thigh-these were strapped on with 6 Straps near each other \& tightly applied-each Strap included Plane within its circum. \& thus secured the Thigh to it-the other inclined plane was covered with a Piece of Flannel \& Leg upon it, two Pieces of Bandage secured Leg to Plane, -a Fracture Box applied, \& then all made firm \& secure. A small Pillow was put on each side of the Leg within Box to fill up \& keep steady. . . ." Some sores developed and poultices were used. "Made O.P. Sept. 26-3 Splints appd. with Emp \& Band. Fracture appears to have been situated just above great Trochanter from which the neck was detached,- a good deal of offensive matter was thrown out as the part was somewhat arched outwards \& very much thicker than the other Limb. Oct. 7 came again-had been walking a little with a stick or two."

Case 20. B. W. male aged 19 admitted on 4 August with compound fracture of tibia. "Accident happened by a piece of Stone falling against back part of Leg which was bent forwards against a Stone or Post, \& then fractured, Tibia itself made wound $\&$ protruded about $\frac{1}{2}$ inch. Fractured diagonally $\&$ it was upper extremity which appeared - there was considerable Contusion \& Swelling of the Limb generally but most particularly posteriorly - as is custom patient was first laid on Side with Limb flexed, but it was found that the Bone in the position of limb pressed against Integuments was therefore laid upon Back with Leg extended \& in this manner Bone (Extremity upper of Tibia) did not put the soft parts on Stretch so much as beforeshould have said that the protrusion of Tibia was easily reduced at first by stretching limb a little-a double Catapl. next applied \& over it 18 tailed Bandage (limb being previously laid upon a Pillow) then straps were applied \& Fracture Box, with Bag of Sand appended to Eel [sic]. . . ." Some inflammation and fever followed, but settled. ". . . till 16th. when the upper \& lower portion of the Tibia having somehow perhaps by his not laying quiet taken on outwards direction \& the lower extremity on inner $\&$ the upper extremity being denuded to abt. an inch of its periostium, it was deemed necessary to remove both the Extremities as there was no chance of straightening the Limb by reposition of the Bones \& as the process of exfoliation of the denuded part would have been very tedious, this done by Hey's Saw, Chain Shares etc. near to skin of bone (of Tibia) were removed, the lower was much shattered $\&$ the Fracture was very longitudinal \& diagonal-Catapl. were applied just as before . . . Splints on sides of Pillow with surroundg. straps ... Sept. 3. Cries all day a little 


\section{S. T. Anning}

feverish \& very restless wh. might in some measure be induced by his having fret for two or 3 days, \& partly from the Patient in next Bed having Erysipelas. . . ." More infection followed and erysipelas. There was abscess formation but slow improvement. "Nov. $14 \mathrm{Leg}$ has acquired some durable firmness-wound trifling but does not heal fast-plaister laid aside, but simple dressings continued-usual as well as Splints made O.P. goes on Crutches."

Case 21. H. M. male aged 57 admitted on 6 August with severe injury of right hand. “. . . happened by hand getting entangled in Machinery by which the Meta-carpal, Phalanges cartilages soft parts of the 3 outer Fingers were so severely fractured, lacerated etc. etc. that it was necessary to remove them by the Wrist-Joint-As much as possible of Integuments preserved to over-wrap-Dressings so applied as to give all possible support to parts \& hand \& Arm enveloped in double Bread Poultice-Enema injected. . . ." Fever, sloughing, and abscesses followed. "18th. Another Abscess opened at the Carpal Extry. of Radius-23rd. as the matter seemed to be continued all along the Arm-Mr. C. was making a counter openg. \& in doing it, unfortunately divided 2 or 3 largish Arteries wh. bled very profusely.2 smaller were with a little difficulty secured, the other much larger one could not be secured, bled profusely, but somehow perhaps with Coagula the Haemorrhage ceased. the tendon of the Index Finger has sloughed, \& the Metacarpal Bone fractured so that it is determined to amputate in the middle of the Arm in a few days.-suppuration very profuse . . . 25 Haemorrhage began suddenly this afternoon, a Consultation called \& limb amputated a little below Elbow . . 31, seems pretty well . . . more shivering \& this Noon, seemed sinking very fast \& obiet."

Case 22. J. B. male aged 36 with paralysis of lower extremities. [No date] “. . . happened to fall from some scaffolding by which he injured his Back \& has since \& immediately after had complete paralysis of lower extremities. Stools be involuntary -had lost his sensations of leg abt. lumbar region all round body $\&$ had not regained least-upon pressure along Spine complained of little pain inter Scapular.-was cupped to abt. $8 \mathrm{oz}-$ had purgation given $\&$ Sul. Eff. on 3rd. day after acct. had a dozen Hirud: [leeches] applied to same part- $\&$ has since taken nothing but Eff. Media: appears to have no chance of Recovery.-is almost constantly flushed but complains of no pain-Catheter passed Statis Horis. 28 Seems sinking fast, no particular Compt.-gradually sinking till p.m. of 30th. \& then died upon Examination of the Spine of that part when he had complained of the Pain viz between Scapulae part of the Arch of one Vertebra was found fractured rather splintered,tho' the bone was in its natural situation, there was a little Extravasation upon the outer surface of the Theca Spinalis for abt. 5 or 6 in. downwards on cutting into Theca, there was a considerable quantity of limpid fluid, part of inner surface seems inflamed, as well as the Cord in wh. were seems [sic] several tinged vessels,-within this lower pt. of Theca wh. was exposed, there was a little extravasated fluid-on the under surface of the Theca, there was a good deal of extravasation, \& which seemed to extend lower than what we examined." 
Case 23. R. B. male aged 18 admitted with fracture of patella on 13 August. "fell downwards pitched upon Knee \& thus fractured Patella-there was considerable Contusion \& swellings. Integuments were drawn upwards \& downwards, towards the Rim \& Bandages applied to retain them in the position but the Swelling pain be increased, \& they were removed on the following day, \& a Catapl. applied to the part, on the 5th. day Swelling had subsided a good deal-\& took openg. \& Feb. Med:A Splint was likewise applied underneath Limb. 27 all Inflamation [sic] being gone the Fracture was put in the following Manner-Integuments less drawn downwards \& upwards by self Mr. C. applied two flannel Bandages, meet approximate each other just above \& below Joint. Strips of Emp. Saponis were then by Mr. C tightly applied in a longitudinally diagonal Manner crossing each upon the Patella \& thus covering the whole Knee. A Common Cotton Roller was then applied over all in the usual way, \& Limb was placed upon Pillow, which was double under the Eel [sic] \& Leg $\&$ inclosed in Fract. Box. 30. . . . a Wedge put under Bed-Cloths to elevate the Foot \& Leg, so as to make the limb more inclined, thereby tending to keep fractured portion nearer to each other.-Sept. 7. Emp reapplied: Union had begun \& fractured Extremities within 4 inch of each \& dont retract. 11th. pt. looser \& retract more, left Emp. To be O.P. Edges of Patella seem to have intracted a little which wd. be permanent, made O.P. came on 26th. Octr. very slight ret."

Case 24. J. T. male aged 32 admitted with severe fracture of humerus on 13 August. "... had the left Humerus very severely fractured by the fall of a Stone-there were 3 small wounds but wh. did not communicate with the Bone-afft. parts were a great deal contused,- was difficult to ascertain whether it was not fractured in two places viz just above Elbow Joint \& abt. 2 in: higher-if not so fractured at all Events the Bones were much splintered-Swelling increased \& extended to Shoulder \& down to Hand which was much swollen,--it was attended with a great deal of Pain \& Redness -Catap. applied . . . Lotio Evap: [lead solution, spirits and water ${ }^{5}$ applied to the Shoulder \& Hand. 24. Poultices applied afresh Skin abraded in 2 or 3 Places upon the Elbow \& Sloughs (small) likely to form-were two or three Ulcerous Excoriations Arm very much swollen \& painful. 26. Limb less swollen \& painful \& two Abscesses opened this Mornig. near the Elbow. A Counter Opening made at the corner of the Elbow to relieve the matter which could not well be actuated itself from the upper Openg. ... has a considerable Fever Opium gr 1 o.n. ... Sept. 2 limb much swollen, 3 or 4 Ulcers on areas in different parts .... on Wound above Elbow Joint, allows Probe to pass quite into the Joint a few days had Erysipelas upon the left side of the Breast,-much serum . . . shrunken in the Countenance-is allowed visitors,-no chance of recovery but by Amputation which must be waited for till Infection gone. Sept 6, 7 seemed sinking under the Erysipelas \& infection of Arm-quite sensible \& takes no support-9 obit."

Case 25. A. D. female aged 9 or 10 admitted with compound fracture of the left leg. [No date] ". . . fell from a highish wall \& suffered compd. Fractre. of Tibia, Fibula

s Ibid. 


\section{S. T. Anning}

was also broken, there was a small wound on the inner Side of the Leg. abt. $1 \frac{1}{2}$ or $2 \mathrm{in.} \mathrm{above} \mathrm{Ankle} \mathrm{through} \mathrm{which} \mathrm{a} \mathrm{Splinter} \mathrm{of} \mathrm{the} \mathrm{Top} \mathrm{part} \mathrm{of} \mathrm{the} \mathrm{upper} \mathrm{Extremity} \mathrm{of}$ Tibia protruded, the Bone being driven inwards-The Wound was enlarged with Scalpel \& the protruded Splinter together with another removed with Hey's Saws, the limb put upon the side in $\frac{1}{2}$ bent position-a little soft dressing applied to the Wound \& double Oatmeal poultice put on-There was not much contusion of soft parts. Bowels were opened . . . 25 Ten Hirud. [leeches] appld. to near the Wound \& Lotio Evap: as there seemed considerable tension between Wound \& Ankle. . . . 27. A little more Inflamation [sic] . . 31 . . . Abscess opened ... Wound discharges well, looks clean \& healthy, inner pt. of leg seems to incline rather too much inwards, but this I think is from the Feathers of the pillow being shook to the out-sideSept. 1st. All infln. gone. Catap. removed Limb put up in extended position, a Pillow with Cloth, \& tailed Bandage with Emp. Saponis applied, sore dressed with simple dressing \& pledgit-1 in. Splint on each side the pillow, \& surounded [sic] with three pieces of Bandage, inclosed in Box in fresh Bed. 2. - discharge rather profusebone dry as before \& clean. 3rd. Sept. less discharge. As the Girl pisses bed, was obliged to be put onto a fresh one on Septr. 6 fresh plaisters Bandages etc. to the Extended position with change of treatment seems to agree very well-sore healing \& leg straight 11th. Another Bed, Bandage, Emp: ... 29. Foot seemed inclining rather too much inwards \& in consequence leg put into short Splints with simple dressings to sore. Emp. Sap. with Flannel Bandages \& Splints with Calico Roller. Leg pretty strong, \& sore healing rapidly -. . . Oct. 1 Wound nearly healed . . 12. Girl jumps out of bed \& knocks about carelessly with her leg-Wound nearly well, made O.P. Jany. 1, 1824 Saw the above Girl, wound healed after a little Exfoliation, \& the Leg is nearly straight—carried a little outwards in consequence of the bone on the inside."

Case 26. M. N. male aged 20 admitted with a severe injury of left arm. [No date] "... got his Arm drawn into Machinery by which the Integuments from a little below Shoulder Joint were nearly stripped of the whole Arm-the Muscular parts were in different parts much contused. \& the Radius on the inner part a little exposed, denuded of its Membranes.-Neither the Humerus, nor Radius nor Ulna were fractured but there seemed to be some fracture abt. the Wrist formed by the Ulna \& Carpal Bone of which in future-Amputation by the Line of the lacerated Integuments was immediately performed. In cutting through the Muscles they were found to be on one side the Arm a little contused which was not discovered or indeed thought of before the Operation.- Straps of soft draping were applied to Flannel BandagePatient put to bed \& took Tr. Opii gut. xxx soon after with an opiate on the two following nights. 25. dressings viz Emp. Cerae \& Bandage removed, \& applied again was a good discharge-Wound looks as well as can be expected ... Edges quite retracted. $26 \mathrm{~A}$ little Inflamation [sic] appears on the Skin surrounding Wound, simple dressing \& poultice applied. 27 Infln. gone, . . . Sept 3 Edges drawn together with Emp. Adhesiv. instead of soft dressing.-All Ligatures came away today except from the Brachial Artery 11th. all Ligatures came away. Abt. Sept 16 a little inflamation [sic] came on the Glands in the Arm pit came on \& seemed to threaten terminate as abscess but all such Symptoms vanished by the application of a poultice 
for a few days-Wound nearly healed on Sept. 26, \& made O.P. Cured Oct. 10."

Case 27. B. L. male aged 17 admitted for treatment of simple fracture of thigh. [No details of accident] “. . . wounded Augst. 25 Mr. Chorley In this case Fracture was highest up \& there was a little Swelling etc. App. Catap. Jup. Septr. 1 Limb being well washed, \& bed ready patient was carried to it, \& limb put in extended position as in Case 15 Josa. Firth. Emp. Sap. applied just as before excepting that Mr. C did not use the 4 small Splints upon the tail Bandage wh. W. H. did. 8 all loosed down \& with Flannel \& Cotton Bandages \& made O.P."

Case 28. J. S. male [no age given] admitted on 2 September with severe injury of hand. "... by means of Machinery had all the Skin, much Extensor tendons be taken at once from the back of [gap in Ms.] so that the Fingers were in a state of Castration, Periostium being denuded, it was upon consultation doubtful whether or no, the Fingers would eventually be of use, or whether if it would not be better to remove them at once-however the chance of preserving them tho' so very small be adoptedlittle dressing applied \& double Bread poultice-there was soon contusion of soft pt. beside Fingers at Wrist wh. would slough-On the 3rd. or 4th. day infn. seemed extending up the Arm, \& therefore Poultices continued upwards, which completely removed it-has had but slight fever. 9th. Suppurative matter always covers the Metacarpal Bones when the dressing is first taken off, but it nearly all escapes with squeezing the Sponge upon it, leaving part of the Bone quite bare-a little colour observed in Bones-a little digestive to be applied instead of Ung. Cerae-Pt. had an attack of Pulmonis infn. for wh. he was blistered, had leeches applied \& took Salines etc. 17 seemed sinking, \& 18th. obit. Remark. The Fatality of the pulmonary infn. in a subject naturally delicate, $\&$ having sustained a bad injury."

Case 29. S. S. male aged 56 admitted on 6 September with a compound dislocation of the tibia, etc. " . . . being intoxicated fell in running \& somehow dislocated the right Ankle,-Tibia being thrown \& protruded through the Skin to abt. $1 \frac{1}{2}$ in length \& 1 in breadth, was likewise fracture of Fibula - of course the Man seemed from his going on to be either an Idiot or very light minded-Acct. had happened between 9 \& 10 p.m. of Sept. 6-reaction had begun \& the parts seemd tense Mr. S. seemed to hesitate between Amputation of Leg \& removal of protruded portion of bone. Mr. Hey between simply reducing Bone \& removing exts. however-Extremity was thought proper to be removed which was done by comon [sic] amputation Saw the Scalpel first cleard. away a little - of course as soon as End of bone was sawed off the Tibia returned easily to its natural Situation, \& Fibula too, a double poultice was applied \& limb put in best position-Poultice renewed daily for 3 days \& under 2 den. die,had considerable fever, . . 16th. a small Orifice nr. mall. extern. upon which limb was laid,-being discovered this morng. the Finger was passed through \& the Fractured fibula distinctly perceived. . . 27. A Rough discovered upon the Eel [sic], only trifling, a small poultice applied with dressings to other parts as before excepting that the leg is laid upon the Side to take off pressure from the Eel [sic]. Wound on the inner Ankle healing kindly, - that on the other Ancle [sic] improving-no bone 


\section{S. T. Anning}

yet exfoliated. Novr. 1 To keep the Foot steadier \& firmer two Splints have been applied, one on each side the Leg with cotton Roller. 16. Wound on the inner Ankle quite healed that on the outer much contracted \& healing fast since the Application of the Splints the leg has acquired a considerable degree of Strength-Jan 23 O.P. . . . . May 1823 [sic] Heard of SS [patient] could make no use of Ankle Joint-several Splinters of bone come away, no Motion,--bear little or no weight upon Footshorter than other Leg in consequence of heel being elevated considerably so that the Toes point forwards, which was the case when in ye. hands."

Case 30. G. T. male aged 15 admitted on 1 November with compound fracture of os humerus. ". . . got his right Arm so twisted by Machinery that his Fore Arm suffered simple fracture of both Bones and the Humerus Compd. Fracture.-There was a Wound on the Underside or inner side of Humerus, - \& upon passing the fingers into it, one extremity of the bone was plainly felt.-in some Measure etc. consisted of Periosteum-Considerable tension etc soon came on, the Arm was put in the bent position with the Fore-Arm elevated by Pillows in an inclined plane- 4 poultices (bread) applied,-Nothing to wound-took some Infusion \& had an injection [enema] in the Eveng. . . . on the 20th. pulse being rather fuller he had oz viii of blood detracted from the Arm,-. . 25. Abscess on the Fore-Arm opened in two places from whence issued a good deal of matter.-is now allowed for the first time a little bread to eat ... 27. An Abscess upon the Hand opened-no Abscess on the Elbow was suspected. 28. A Counter Openg. made on one side of the Arm to give Exit to matter which had to discharge still upwards, is now allowed a little Bear [sic], Meat. . . . Decr. 3 . . about 10 o'Clock P.M. all at once without previous premonition the Brachial artery from ulceration (as afterwards appeared) gave way \& a deluge of blood issued, tho' it was in great measure restrained by the Bandage round the Arm-in a minute or two compression was made by the Fingers above the Rupture of the artery until the Tournequet [sic] was procured \& applied as well as the Subclavian Key.-He seemed very much reduced by the haemorrhage, Wine \& Brandy Gruel were administered to keep up the Vital Powers, \& as soon as a Consultation could be had (in about $\frac{1}{2}$ hour) the limb was amputated-during the operation he vomited a good deal, \& seemed in fact upon the Threshold of Death's door, warm gruel occasionally with a little Wine was given during the Night \& in the Morning he seemed a good deal recovered, $\&$ has since continued in an improving conditionDisd. O.P."

Case 31. H. P. female aged 11 “admitted January 2 at 6 o'Clock P.M. for a Compd. Fracture of Tibia \& Fibula of left leg with simple Fracture of right Leg. Accident happened by the Girl's legs being caught in a revolving part of Machinery. There was a wound perhaps four inches long across the middle \& fore part of the Leg, the Edges of which had retracted in the middle to about 2 inches, thus exposing the fractured Tibia which was denuded of its Periosteum \& Fractured obliquely. Fibula was broken $1 \frac{1}{2}$ ins above the Malleolus the Contusion of the soft parts was very considerable, the Bone did not protrude through the Wound. The right leg was severely contused $\&$ had suffered a simple Fracture about the middle the ligaments 
of the Knee appeared in some degree lacerated. The Femur of the left Leg was broken off just above the Condyles, not the slightest injury was done elsewhere. Under all these Circumstances it seemed quite impossible that the Girl should recover exempting by amputating the left limb above the Knee, thus reducing it to a simple stump. From the violence of the Contusion in the other \& the Emphysematous feel there is great reason to apprehend Mortification which may probably more extensive \& serious their impact that Constitution may be able to bear up against,-The Mother obstinately refused Amputation which was proposed to her as the only means of saving the Child's life,- the Child was very languid \& weak, \& in [sic] seemed in fact as if it would hardly rally from the first shock of the Accidt. As the Mother refused the immediate Operation, a Consultation was resumed $\frac{1}{2}$ p. 7 next Morng.-in the mean time attempts were made to induce reaction \& a restoration of the Vital principle locally as well as generally-there was pretty fairly exhibited internally-the Feet \& legs were wrapped up with warm flannels \& bladders bottles of hot water applied $\&$ frequently renewed. Tinct. Opii $\mathrm{mn} \mathrm{x}$ were given-The Child had a partly comfortable Night \& seemed a good deal revived-Amputation was therefore performed above the Knee of the left limb, \& the right was enveloped in a double poultice \& surrounded with hot Bladders ..." She developed gangrene of the stump and the right ankle and on 14 or 16 January she died.

Case 32. M. S. female aged 43 admitted on 19 January with compound fracture of the left leg. ". . . happend her Accident by a loaded Coach passing over the leg with both Wheels-when she was brought in there was a slight Wound upon the Fore \& middle pt. of Leg through which the finger being introduced the Fracture of the Tibia was distinctly felt. Fibula appears not Fractured." Attempts by extension to approximate the fractured ends of the bone were not successful. Abscesses formed and the fibula was found to be fractured and protruded just above the malleolus. On 10 February there was haemorrhage with the loss of about seven pints of blood for which compression was applied. "About 1 o'Clock p.m. of the same day it again returned \& 1 pt at least was lost before it was stopped \& in 2 or 3 hours afterwards she sunk."

Case 33. G. H. male aged 51 admitted with retention of urine. ". . . admitted on Die Martis $10 \mathrm{mo}$. Feb. at noon-Begun on the Afternoon preceeding [sic.] with very great pain in making water of which he could get quit of very little only in drops. (This difficulty \& pain in micturition he had had more or less for a long time back from Stricture)-The report getting worse all the Afternoon \& Eveng. when he first perceived a very small swelling of Scrotum. This he fomented by the Advice of Flood, ${ }^{6} \&$ also took some Med.-The swelling quickly disappeared, still the pain $\&$ inability to micturate continued all Monday night till about between $9 \& 10$ o'Clock on Tuesday Morng. When the Scrotum in $\frac{1}{2}$ Hour acquired an immense size with Gangrenous Vesicles. For all the Night \& Monday Afternoon \& Evening. had a constant desire to make water, but all attempts were fruitless. 1 to 2 p.m. on Tuesday

- John Flood, surgeon. Edward Baines, History, directory, and gazetteer of the County of York, 2 vols., Leeds, [the author], 1822, vol. 1, p. 52. 


\section{S. T. Anning}

Gangrene seemed to have extended a little since morning Mr. C therefore determined on Operating Stat. with a Scalpel he made an oblique Incision in Perineo \& cut down till he came to the membranous part of Urethra when he introduced the Trocar $\&$ evacuated the Bladder of about 6 oz. of water. leaving Canula in the BladderPatient put to Bed \& had given Stat Bolus cum Opium gr ii Calomel gr x \& Pulv. Alt. [rhubarb, mercury with sulphur and guaiac ${ }^{7}$ gr iii etc allowed nothing but Tea, \& Gruel. Scrotum constantly fomented with Fol Papav \& Spts Vin:- -seemed to be a little relvd. by the Operation ... 11. has had a restless night, canula not being fixed in Bladder has come out \& cant be replaced, Mr. C. therefore punctured the Vesica in by Rectum leaving Canula in \& applying a Bandage with Compress over it. By Night some how or other Canula had again got between Rectum \& Bladder tho' it was within the Wound. Mr. C. readily replaced it, \& it was again fixed as before \& Catheter to be introduced within Canula in night-time twice to evacuate Bladder. This was easily done 1st. time but before the second had had a Stool wh. displaced Canula between Rect. \& Bladder tho' it gave the look as if it was alright. It now could not be put to rights-. . 12. No water was now got quit of but what came by the Artificial Openg. already made, \& it did not come sufficiently thro' then.-more therefore seemed collected in Scrotum which swelled more \& sloughing seen extending - larger Incisions made in Scrotum to evacuate the Water, \& from there together from the Artificial Opengs. he appeared to flow sufficiently. . . . Mar: 2. a small wax Bougie passed into the Bladder \& allowed to remain an hour a little water followed its withdrawal - nearly all the Urine flows: pr. Scrotum \& the Bougie has been passed daily \& remaining about an hour in the Canal,-when it has been withdrawn \& a quantity of water has followed,-... Mr. C. this morning passed a Bougie without much pain \& any difficulty, $-\&$ in a Minute or two withdrew it \& immediately passed a Catheter,- then Catheter remained in Bladder all day \& the Water discharged at intervals-the Catheter was taken out at Night, consequently the Urine flowed pr. Scrotum. -2 or 3 times during the Night. Mar. 10. thinks the Catheter which was in all day yesterday has made the pt. more tender.-passed a Bougie this Morng. \& almost immediately afterwards a Catheter it remained in as yesterday. . . 14. Mr. Chorley wishes this Morng. that Catheter should be with drawn \& introduced when he wants to make Water, during the day \& to remain in all Night ... 15. Catheter withdrawn \& another put in ... Wound healing very fast since all his Water has passed pr. Penem.-Passing Urine by the Catheter appears a great point gained. ... Improves of himself. Apl. 6. has been going on as usual since last rept. Catheter withdrawn \& introduced first call once a day.-In the course of this day (the Catheter being out of bladder) having a Stool a small qnty of Urine wh. happened to be in ye. Bladder came by the Penis . . 24. Went into Town-came back drunk \& has since been at home. May 2. been to see the Patient, find that the Wound is nearly healed. Made use of the Catheter himself the day he went out \& once next-has come less \& less pr. Scrot.-attends some easy work of the White Horse daily."

Case 34. C. B. male aged 35 admitted for fracture of skull "Die Veneris 26 Mch 1824 -recd. his Accident about 2 o'Clock p.m. by a Porter Barrel rolling with great

${ }^{7}$ Anning, op. cit., note 3 above. 
force against his Forehead, \& sending it against a wall. came in about 4 o'Clock-There was a Wound on the Forehead rather cruciform in figure, the longest line going upwards \& downwards, $-\&$ perhaps 4 inches,- to the superficial Observer the bone was fractured \& depressed-Upon introducing the Finger in thro' the Scalp the External Table was felt fractured \& depressed on one side,--there was a fissure which went thro' at perhaps an inch distance \& its communication with the depressed side - had been no insensibility since the time of the Accident happening, face was much swollen. It was not ascertained the internal table was fractured till Mr. C. was removing or elevating a plate of the External Table-when the Brain all alone came into view-The dura Mater was not wounded. The Operation commenced by dilating the wound a little,-clearing away clots of blood \& extracting with the Forceps small loose pieces of bone,-next sawing along the fissured side of the Fracture, a piece was extracted about the size altogether with other bone fragments of a penny-at first it was thought that only the External Table was fractured but when a large piece of bone was removed with Jaws, Chisels \& Forceps-the pulse of the Brain was brought into View-rather more of the internal than External Table was broken, -quite sensible all the Operation. a few strips of Emp. Adhesiv. one ligature at two of the Angles, \& the remainder of the Wound covered with Empl. Cerae \& Lint covered by a flannel Bandage consisted of the Dressings.-After his Operation took Tea, ye. shock gone has had little pain. Face much swelled. . . 15 Apl. has been quite well since last Rept. for a few days back has sit a few hours.-May 7 Wound being quite healed $\&$ all being well of himself discharged Cured."

Case 35. W. A. male aged 45 admitted with a wounded larynx etc. [No date] "—-admitted early in the Morning - being for a little while previous to his Acct. in a long despondering way-at 9 to 10 o'Clock of the Evening of Mch 6. being alone in Privy with a Razor (wh. was dull as appeared from his having made several Cuts) cut across the fore pt. of ye. throat:-The Incision which was about 5 in. long nearly severed in two the Sterno-cleido-Mastoideus of the right side. The same muscle on the other side [left] was in pt. divided. The Larynx was opened between the Thyroid Cartilage \& Os Hyoides, so as to fully expose the inner Cavity when turned.-The Act of deglutition \& talking made the Trachea ascend \& descend alternately in a very striking manner, - a small artery was divided by wh. he appeared to have lost a largish amt of blood, as when he came in he appeared very faint $\&$ pale $\&$ ghastly in ... [?] The Wound upon separately [sic] the Integument was very deep \& the finger introduced was placed upon the Carotid of the right side-this Artery divided was secured.-The lips of the Wound after cleansing away all coagula the rim secured by 4 or 5 Ligatures alth. there was a great disposition for it to gape open-it was then dressed with Emp. Adhes. patient put to Bed with 3 or 4 Pillows between his head \& Shoulders to make the Chin approach as near as possible the . . [?] by this means the Edges of the Wound were kept in contact-\& vice versa-A little Wine $\&$ water was given in ye. sustane to revive the poor fellow-but for a few first days was allowed nothing but liquid Slops ... The Wound dressing daily. in consequence of the almost impossibility of keeping the Lips in contact, it suppurated \& gaped quite open ... The Wound contracted rapidly, \& by the Contractions the Ends on 


\section{S. T. Anning}

each side of the Throat wh. were at first furthest distant became as near to each other as the other two-therefore Emp. applied to second it-did curb \& Made OP. Apl. 2 had hoarseness-is talking."

Case 36. W. N. male aged 35 admitted on 5 May with retention of urine. ". . . has had strictures for 6 yrs. - could make water in a pretty good stream till Monday Night May 3rd. when he unexpectedly found he could not part with any.-he continued dribling [sic] all Night till Tuesday Morn: getting quit of only a few drops at a time-continued in this State till Tuesday Afternoon when every Effort began to be attended with Pain, however he now started more \& passed a pretty fair Night on Tuesday so that he thought he was getting better-indeed thinks he got his bladder emptied. On getting up on Wednesday Morning he was again attacked as bad as ever-Water now \& then dribbling with pain in Body.--voided less \& less \& came on about 4 o'Clock pm.-his Body was now getting quite tense above the Pubes, with pain. . . . Baln. tepid. . . . . after coming out of the Bath he fancied he felt a little easier, tho' he could not make more water.-still no Urgent Symptoms, seemed quite cheerful lively \& undismayed ... thus he went on till about 10 o'Clock his water continuing to dribble intervallis, \& quite restless, walking about Room.Mr. C. just tried a Catgut but did not pass it: . . It was upon Consultation thought proper to puncture ye. Bladder by Rect.-which was done \& from 2 or 3 pints evacuated: This gave very great relief-Canula was kept in ye. Bladder without giving any pain or uneasiness till Jovis 13 May-when it was withdrawn-... Bougie tried on Thursday the 7th. day of the Operation, but smallest wax one could only by [sic] made to enter Stricture a very little which felt tight, \& about middle of Urethra,allowed to remain in about 5 or $6 \mathrm{hrs}$ daily.-Solis $16 \mathrm{Mr}$. Chorley took a Catgut but was not able to pass beyond the Glans Penis but upon trying a small Elastic Gum one it went home to ye. Bladder almost without opposition-This was suffered to remain in till he wanted to make water-This was again introduced on Monday $17, \&$ remained in an hour Through he was enabled by the mere introduction of the Bougie into Stricture to pass water better \& maintain a stream, but since it has gone into ye. Bladder he has been very much better in Micturating-18. Not being quite so well, rather feverish irritability the Urethra was not meddled with -A little Mucopurulent discharge has shown itself after passing Urine 22. The same Elastic gum Bougie as last was without trouble introduced today, immediately withdrawn another was very $\mathrm{nr}$ twice its thickness carried in almost with as much ease-\& allowed to remain in $\frac{1}{2}$ Hour. 24. A Bougie twice as thick as last introduced with almost as much facility but gave rather more during its abode in ye. Bladder-next day a little coagulated blood discharged itself in Clots, so that Urethra was rather irritable for two or three days, \& in consequence no Instrument passed till about 31 O.P."

Case 37. J. M. male aged 49 admitted on 18 May with compound fracture of tibia etc. "... under Mr. Hey during whose absence Mr. C. officiated. The Acct. happened by a Cart passing over his Leg - there was a Wound upon the Fore part of Tibiaupon introducing the finger several Splinters of Bone were seen \& felt-The man is 


\section{The practice of surgery in Leeds 1823-1824}

stout, - had injoyed [sic] good health $\&$ is ye. Father of a male $\&$ large family. Though there is no external Communication the Fibula must be fractured from ye. looseness of the Foot \& Leg-Mr. C. inlarged [sic] the Wound a very little \& dissected out Splinters of Bone perhaps 6 or 8 no. \& 6 as in all together to make about in. 1 [sic] of the Whole Cylinder of Tibia just above Ankle Joint. Two or three of the pieces were removed by Saw-When all the loose bones were extracted, angles sawn off \& filled, a little simple dressg. was applied, Leg laid in bent position upon a piece of Emp. Sapon. \& covered with Catapl. Aben. Then poultice was renewed daily-took an Opiate after his Operation \& nightly afterwards-Bowels opened by InjectionAll seems to go on pretty well till Sunday Eveng. when he began to experience more pain than usual in Calf of Leg, which he attributed to its jumping spasmodically. I was sent for \& found there had been some Bleeding evidently arterial perhaps $4 \mathrm{oz}$. this induced me to take off poultice, but found it had stopped-in an hour or so it again bled a little \& I then removed poultice \& applied Lot. Evap. flead solution, spirits and water ${ }^{8}$ ] took Opiate-before seeing him on Monday Morning found he had had a severe Rigor followed by copios [sic] perspiration but then seemed as before excepting pulse rather quicker \& altogether a little more feverish.- limb more swelled, inflamed \& painful.-About 3 o'Clock pm all at once an Artery gave way \& discharged perhaps oz xxx of blood in a minute or two-now stopped spontaneously-was much reduced \& a little tr administered-Consultation about 5 o'Clock it was determined to amputate-Coagulas of blood were cleaned away from wound by sponges $\&$ finger but vessel could not be caught but did not bleed.it was done by Mr. C. about Calf of Leg in a circular manner \& dressed with Emp. Cerae \& Poultices-Beef Tea \& Opiates. Tuesday, Wens. 25 May-having had no stool--an Enema ... delirious ... sudden loss of blood . . . Upon cutting open ye. Wound it seemed sloughy \& it was found the anterior Tibial Artery had ulcerated ... All appeared doing well,-in a week or ten days the Stump which had been very foul got cleaner \& inflamation [sic] gradually subsided.-... the Edges of ye. Wound which had been very wide having now got clean $\&$ healthy contracted rapidly $\&$ in the course of a month was quite in contact $\&$ looked as if it would soon be well-... Wednesday P.M. June 9-had a violent shivering which lasted more than an hour-. . . He continued much in the same state till about Solis or Lund 13 or 14th. complaining of no pain but constantly swetting [sic], shivering in quickish breathing - pulse feeble \& very quick during this time it was hoped he might recover but after Monday the 14th. he began to get weaker considerably by the perspirations -... he had daily a very smart rigor which lasted an hour abouts during which he was so much exhausted as to appear to be sinking - after Monday he gradually sunk getting weaker \& weaker \& expired June 20. Dissection."

Case 38. J. D. male aged 11 admitted on 25 February with compound fracture of ulna, etc. ". . . under Mr. Smith got his left Arm entangled in Machinery by which the flexor Muscles situated nr. about the Ulna a little below the Elbow-Joint were a good deal lacerated.- the Ulna broke $\&$ an extremity to be felt in the Wound but which had not protruded.- - the Integument was also torn down the Arm so that the

I Ibid. 


\section{S. T. Anning}

Radial [sic] was discovered quite exposed, \& looks pr. se-Bones not protruding in the Arm admitting of being put straight with bones in easy coaptation, this was done $\&$ soft dressings applied with Captapl. \& in the subsequent inflamation [sic] $\&$ sloughing were not particularly severe $\&$ he seemed to be doing pretty well till 5 or 6 wks when he began to fall off of himself-the cause of wh. was not at all apparent wn. the Arm was dressed-granulating fast when there had been a loss of parts however in a few days a swelling was discovered near the Clavicle \& wh. evidently contained matter-a Catapl. applied \& when it got more superficial a puncture was made \& it discharged a great deal-upon passing the probe it was found to go through the muscle almost to Axilla-the lad still continued feverish \& falling off in Appetite . . . perhaps 14 days a counter opening was made in Axilla-these two discharged a good deal while matter seemed to extend all around the Joint, so that swelling was still kept up-he kept going on in a very poorly way for several weekswas very much reduced . . . in ye. latter end of Apl. he began to mend a littledischarge diminished \& in consequence swelling of Shoulder gradually subsidedhe rapidly in May recovd. . . . by the End of May abscess has quite healed upleaving bone $\mathrm{nr}$ Joint not affected functionally by it-His Arm had all along been going on tolerably but rather slowly ... Being so much recovered of himself \& Arm requiring only simple dressing he was made O.P. May 21.-been in nr. 4 mos....."

Case 39. J. C. male aged 32 admitted with compound fracture of thumb "admitted Mr. Smith May 17. Acct. had happended eveng. previously by a chunk of coal jaming [sic] it against something, no-other pt. suffered any Contusion except Thumb-the first Phalanx was fractured \& one Extremity protruded just above ye. Nail,-it was readily reduced-simple dressings applied \& poultices recommended.-given next Eveng. - said it had been very painful hand was swelled,-was taken into ye. Hospital lay to Bed,-his hand put in double Poultices, \& Lot. Frid. Applied to Arm. - the swelling extended up ye. Arm \& was very painful getting worse till Friday 21st. still nothing particular or serious was apprehended, was thought merely a very violent attack of inflamation [sic] consequent upon ye. Injury-he was very feverish-had taken a little Aperient, Jalep Eff.-hand \& whole Arm on Friday Eveng. (21st.) was very hard, much swelled $\&$ had four blisters here $\&$ there, - on looking at it on Saturday Morning it was found, the whole limb was becoming gangrenous-thumb itself into mortified hard blackish \& pt. of Arm also, with Cuticle peeling off, he was still quite sensible and did not make any particular Compt. of Pain, ... the gangrene still kept extending all day \& by Eveng. his whole Arm to above Elbow was quite mortified, - . . all Fingers now quite black-gradually sunk on Saturday night." Died.

Case 40. J. I. male aged 32 admitted with contusion and compression of spine “. . . admitted under Mr. Hey May $191823-O n$ ye. 3rd. last was carrying a piece of heavy timber,- he supporting one end \& another man the other End, when suddenly the other person let his end fall, by which the patient unexpectedly recd. of severe contusion over the Shoulder, as well as Concusion [sic] of whole Body, -he fell 
to the ground by this Force \& afft. shock,- -he got up \& thought he felt nothing much worse, excepting a severe shake. he worked all next day as well as he could expect, but fancied he caught cold, with Night and began to be shivering $\&$ feverish -became attacked with pain in ye. Back, numbness of extremities \& he continued getting worse. Confined to bed, to ye. day of admission, - - he was now very feverish his pulse very full \& quick \& strong, face much flushed, pain all along back (Spine) particularly on pressure, almost total inability to walk with great numbness in Legs. . . . blood was exceedingly cupped-felt next Morning considerably relvd. of himself, pulse come down- ... on the 13th. had sixteen Leeches applied to the Back which gave much relief-Catapl. cont. Med. Sal. could make more use of his Legs-in 2 or 3 days had some Leeches applied to another pt. as pressure at one time severe pain in a different pt. always to what it had done before-in a few more days was cupped inter Scap. Fever had now considerably subsided, could walk much better even without assistance and by continuing his Med. with low diet together with what had been done by then. 28th. could walk without any difficulty, Fever \& excitement being gone off in a great measure he was ordered Mist Camph. in Liq. Ammon. Acet. tds."

Case 41. C. N. male aged 37 "Injury of ye. Body Mr Ch May 6 ... fell from a loaded waggon the wheel of which passed over his Body,- he was brought Stat into ye. Infy. in great pain of back \& body-seemed to complain most upon pressure on 2 or 3 of the dorsal Vert. nothing particular was discovered there by examination,could move his limbs very well-... had also considerable pain in his Body-about Stomach-his pulse was very feeble $\&$ slow, vital powers much sunk tho' a very muscular stout man-altogether a considerable degree of anxiety for the consequences of the Acct. was raised. . . . he continued for a few days in a very doubtful state, being unable to judge of the degree of Injury - occasionally vomited some green coloured fluid, his pulse quick but not particularly feverish,- - complaining of no acute pain-weariness with some pain his Body before the weeks end appeared mending, his stomach settled, bowels open-felt easier-kept gradually improving to the 21st. when he made O.P."

Case 42. A. W. male aged 16 admitted with erysipelatous infection of leg. Mr. Hey "admitted Apl. 2 for an inflamation [sic] of the Leg which had originated spontaneously about a week before-it was very violent and in a few days matter seemed forming \& up.-at least so appeared on his admission-pad poultice applied \& next day an Abscess of the Leg was opened \& discharged a large quty. of matter,-bone [Tibia] bare. - he had been very feverish, but the Fever was rather declining, taking Sal.-in 2 or 3 more days another counter openg. was made in ye. Leg, it was necessary to cut deep to get to the Matter,-tho' he had been a healthy lad, his strength was much lowered by the discharge \& Fever.-In about a week after his admission 3rd. openg. was made nr thigh on front of the Gastrocnem. as a counter one-this also discharged profusely- $\&$ there was a slight haemorrhage but which was not noticed-however about Noon ( 3 or 4 Hours after the Abscess had been opend.) he was in a dying status-the wound was examined \& it was found that there 


\section{S. T. Anning}

had been a largish discharge of blood.-but which was quite insufficient to cause death, had it not been for the great reduction of strength consequent upon ye. discharge of matter-was quite colourless, \& weak-died soon after."

Case 43. W. W. male aged 24 admitted with compound fracture of arm: radius and ulna. ". . . admitted Mch 10 under Mr. Hey, for above accident which had happened by some Machinery. There was a large Wound across fore-arm,- the flexor Muscles being quite divided an artery? [sic] divided amongst the jagged muscles, the bones protruded-Two or three small portions were sawn off so as to make Arm easily keep straight with tightness-Soft dressings applied with double Catapl. Arm elevated upon Pillows-For a few days the inflamatory [sic] symptoms ran highish, but as soon as the parts became cleanish the Fever $\&$ infn. went off very kindling, leaving only one small abscess. - so far as first or inflamatory [sic] Symptoms. he did wonderfully well.-As soon as Wound got cleanish he was dressed in the usual way, tail Bandages etc.-There appeared a great disposition for the upper portion of the Fractured Ulna to break thro' the Skin at its Exty. when all the Slough had separated but upon applying a small pad \& Splint with ... [?] Ligature, in the course of two or three weeks it got depressed very much, \& a little while after got into its right situation. - he continued doing well, till bone had ny. healed, perhaps in $3 \mathrm{mns}$. then being only two small holes indicating carious bone-now had Emp. Sap. to be applied-made OP Cant lift his Arm, little or no Use."

Case 44. E. R. male aged 29 admitted on 8 July under Mr. Chorley with a fractured skull. ". . . About 4 o'Clock p.m. the Man coming home with a Cart horse the horse struck him \& fractured his Skull, the right side of his Os Frontis-There was a smaller wound thro' which the Bone was felt depressed-Operation took place about $6 o^{\prime}$ 'Clock $\&$ finished before 8-the depressed portion when removed by Hey's Saw making a deficiency of bone marked out afterwards-After Operation put to Bed \& a little Tea administered.... Lunae 19 die. Wound been dressed partly with Emp. Adhesiv. \& soft dress. Catapl.-nearly all healed by first intention. - a little discharge from one place, in Angles. Martis 20 die. Integuments a little puffed \& there appears a small Lodgement of Matter-App. Catapl. Continues well himself."

Case 45. A. E. female aged 33 admitted with strangulated femoral hernia "admitted July

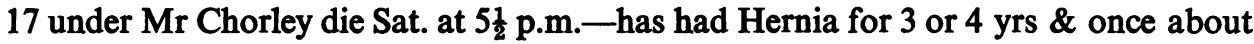
2 or $3 \mathrm{mns}$. ago had it strangulated but Mr Taylor managed to get it up with a little Trouble. [Both M. and Robert Taylor Surgeons in Leeds. ${ }^{2}$ ] Sat. 17 die 6 p.m. Hernia has in present instance been down since 11 o'Clock last Night, during all which time she has been in great pain of the part \& been constantly vomiting everything she took. No Stool. pulse 90 \& smallish. tongue white, skin warm-has had no attempt till about an hour since to make the Hernia ascend-App. Vini Frigid. 8 o'Clock Baln. tepid. . . . a slight attempt to reduce the Hernia in ye. Bath failed - the trial before made by Mr. Taylor was rather violent \& gave great pain-Enema Tabac. st. post Baln. Then Enema came back immediately, was very frail \& exhausted by it

- Baines, op. cit., note 6 above. 
\& Bath.-Hernia stationary-10. Cl. pm Operation. pulse 90. 11. p.m. 01. Ricini

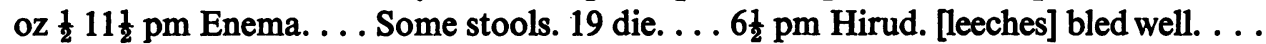
23 die. No pain, easy Night. ... Stools. ... Martis Aug 3 has been going on quite well . . . Stools . . - got quite well-." [For operation on strangulated hernia see Astley Cooper. ${ }^{10]}$

Case 46. T. S. male aged 32 admitted with compound fracture of left tibia and simple fracture of fibula "admitted under Mr Hey-Acct. happened between 5 \& 6 p.m. of the preceding afternoon by fall 7 or 8 yds. down upon a Rock of Stone-lit upon his Feet but thinks the greater weight came upon his left Leg.-when he got up he found his Leg fractured with the Extremity of the Tibia protruded thro' his Stocking -had a Catapl. applied by a Bone Setter \& was left here next day (present) \& arrived at Infy. about 5 o'Clock pm-The Limb was considerably swollen \& inflammation had commenced, was painful \& had had no rest since time of Accident.-There was a Wound upon ye. middle pt. of Tibia there which upper fractured Exty. of bone protruded, but the least possible-This Exty. of the broken bone felt as if was driven inward or rather on ye. inside \& somewhat upon the inner side of Exty. of lower portion-The lower portion of Bone was most external \& its exty. felt at least an inch higher than end of upper, so that upper in some measure seemed to lodge upon inside of lower-Consultation was held at 7 o'Clock when it was determined to remove a portion of bone as there was no chance of keeping the Fracture in proper Apposition without it.-This was done by making a longitudinal Incision to dilate ye. Wound, when a loose portion of bone lying on exterior surface or side was discovered \& readily extracted by Forceps-the upper inner end was then easily sawn off by Chain Saw, - a lower extn. was also removed by Chain Saw with-out any trouble ... limb then of itself went straight ... . Sept. 26 The lower Exty. of bone which had for some days back felt loosish was thoroughly removed by Forcepsbeen doing well of late excepting a trifling degree of infn. which showed itself about a month ago-30. the Upper Exty. of Bone with within layer nr. about 3 inches long was this Morning separated or rather extracted with Forceps." No further details are given.

Case 47. W. F. male aged 3 admitted with compound fracture of tibia and fibula "admitted April 21 under Mr. Hey-happened by falling some distance upon some Stones-was a large wound upon Forepart of ye. Leg about the middle \& directly across-portions of Bone $\frac{1}{2}$ to $\frac{3}{4}$ in length were sticking amongst the contused Muscles. no particular Artery was divided, the loose pieces of Bone were removed, \& the irregular Exts. of more, so that an inch or more might be removed of both BonesThe limb was put in a double poultice \& inflamy. Symptoms being rather mild, no Abscess formed he was drest about 10 or 12th. day,-from the luxuriance of the granulations the bones were lost sight of from first \& never afterwards-he remained in the House till [sic] when the Wound got nearly well,-_appeared no bony union from the mobility of the Bones-still the lad could bop about very well, \& indeed p. 79.

10 Sir Russell Claude Brock, The life and work of Astley Cooper, Edinburgh, Livingstone, 1952, 


\section{S. T. Anning}

was very unmanageable,- - he was made O.P. \& wore short Splints till Sept 18 when all wounds excoriations etc being healed they were taken off \& nothing but simple Bandage employed."

Case 48. T. N. male aged 56 admitted on 1 May with fractured left thigh. ". . . happened in a Quarryhole-limb above Knee in particular much contused-fracturd. just above Condyles-a slight wound situated on outer side-appeared as a punctured one-no communication with ye. Bone-limb was laid in an inclined plane upon Emp. Sap. . . . an Abscess or two formed only in 8 or 10 days which being opend. discharged \& seemed disposed to do well . . . May 17. when infn. (erysipelatous) having left thigh ... further Abscesses ... opened ... June 20. . . began to improve ... Union just beginning . . . Augst. 27 having got tolerably strong made O.P."

Case 49. B. R. male aged 61 admitted on 20 May with severe fracture of thigh. “... Accident happened in a Quarry Hole-was considerable Contn. Femur fractured just above ye. Condyles, on the outer $\&$ upper end of the Tibia there was an extensive laceration of Integuments laying bare the Fascia \& likewise exposing the Capsular in a small degree-limb was laid in as best position \& for a few days seemed to be doing well but now inflamn. \& Erysipelatous caught him . . . June 14-all inflamation [sic] seemed On ye. wane . . . July 28 . all bones being nearly healed . . . short Splints ... allowed to sit up ... doing well till Aug. 6. when he was made O.P."

Case 50. J. N. male aged 40 admitted on 16 July with compound fracture of tibia "under Mr. C from fracture of Tibia just above ankle joint- happened by falling 3 or 4 yds. from a Ladder with a heavy weight upon his Back down upon some flags. There was a small protrusion of ye. anterior part of Tibia the tip or Exty. of which was sawn off and then reduction very rapidly accomplished. He was placed upon his side \& his limb enveloped in a double lineseed [sic] poultice . . . next day delirious ... Aug. 6th. symptoms of collapse . . . abscess opened . . 26th. Three or four more abscesses opd.-vital powers so much sunk that he died same day."

Case 51. S. H. male aged 26 admitted on 2 July "under Mr. H. for some pain in his head but made no complaint of his Retention ... purgative ordered ... On going round next morning ... found that he had passed no water that or preceding day. This lead [sic] to an enquiry into the History of his Complaint which is as follows. That about $4 \mathrm{mns}$. since he began to be out of health-had almost constant vomiting which reduced him greatly, - had also pain in ye. Stomach, Chest, Side \& Back. A Month ago his Water first began to [be] expelled with a little Straining \& had in it when settled a little slime-he wanted oft to void his Water \& if he did not indulge his feeling, he could not retain it-it also used to pass of unconsciously \& wet the Bed occasionally as a Fortnight since he had a pain across the small of ye. Back, felt cold \& chilly, \& this has continued more or less ever since. . . . Finger introduced within Rectum discovered a large Body above the Prostate (wh. was not enlarged) $\&$ wh. did not appear to be ye. Bladder as no fluctuation could be felt. Catheters of various Sizes, elastic \& Silver Bougies, all faild in getting into ye. Bladder. The first 
opposition they met with was at ye. Glans penis, this being passed no part . . . encountered till it was supposed the head of the Catheter got to the prostate.- There it stopped \& was from what cause seemed very puzzling.- but as an Instrument did arrive at the Bladder, still a small Qnty of water preceded by pus was discharged by a violent effort that seemed to be induced by the presence of the Instrument. By all the Instruments used perhaps $6 \mathrm{oz}$ of water was obtained that offered considerable relief, not from pain because he had little, but from causing a stiffness in the Contractions of the bladder-had now a dose of Ol. Ricin. \& Enema . . . Opium . . . Bath ... sickness \& vomiting - Felt easier in Bath \& made a little water. . . . 18th died suddenly." A large tumour "as large as a child" was found above the prostate containing a "large number of hydatids".

Case 52. C. H. male aged 36 with retention of urine "admitted July 2nd. under Mr. Smith. - came in about 6 p.m. having been unable for some Hours to part with any water excepting in Drops-has had a tight Stricture for some Mhs. \& has also had 3 or 4 other similar attacks of Retention to the present, but als got relief as he says from taking Med.- has had Bougies passed which have caused a flow of blood to a largish Qnty. at various times \& has now strong Efforts to get quit of water but is unable except in Drops-no particular pain, \& bladder not much distended, immediately of course attempted this introduction of the Catheter which after readily enough when all at once perhaps 3 oz of blood issued thro' the Catheter \& no water. I then withdrew the Instrument and then bleeding ceased almost directly. In perhaps $\frac{1}{2}$ Hour Mr. S. attempted it a larger Qnty of blood followed. No water. Nor did he get into ye. Bladder. . . . Immersed in warm Bath after $15 \mathrm{mn}$ he made a little \& although felt easier after coming out of Bath he took 1 F.G. every $\frac{1}{4}$ Hour to 5 when he vomited \& was completely nauseated-he now parted with more water, \& his Bladder gradually before Morning, got empty. ... By Noon he got up \& went about -so a small Catgut was tried to be passed but could not next day." No further details given.

Case 53. R. T. male aged 42 admitted with simple dislocation of the knee joint. "admitted July 6 under Mr. Chorley-Acct. happened by falling sideways with the lame leg under him, whilst carrying a heavy weight upon his Shoulders. [Gap in Ms.] There was very considerable Contusion \& swelling of the parts etc, above, \& below ye. Knee Joint-no particular pain when quiet. App. Catapl. Abense . . . Then Lotion was continued without anything else to poultice with a relaxed state of limb upon a Pillow till July 14 or 15 th. when it was put up on like a simple Fracture. The Tension \& swelling had very greatly gone down $\&$ it felt quiet easy." No further details given.

Case 54. J. K. male aged 32 admitted on 8 June under Mr. Smith with compound fracture of leg. "The subject of it a stout muscular Chap, \& nimble, or at least a good deal that way was knocked down by some fellows from a plank to 2 or 3 yds. discent [sic] upon some Earth, \& was I believe beaten by them,-The Tibia was fractured just above ye. Ankle Joint, \& a small point protruded thro' ye. Skin \& 


\section{S. T. Anning}

ye. Fibula was also broken. The Man did not appear to have suffered other injury. Gentle Extension of the Leg returned the protrusion into its situation-limb was laid in double poultice-little inflamation [sic] came on-By June 11th. he was removed upon another Bed, limb extended-simple dressings to Joint \& Emp. Sap. to LegOn the Eveng. of the 12th. he manefested [sic] signs of mental abberation [sic] sitting up in Bed, \& getting off the dressing-Prior to this he had shown no signs whatever of any thing of the kind-only thing I myself noticed was he always had a rather peculiar wild vacant stare of Figure of Court. 2 am-this leg was laid on its side \& a poultice applied and an Opiate given-pulse quick but not full-he gradually got worse \& worse by symptoms similar to those of Typhus Fever came on rapidly $\&$ by the 15 th. he was without any excitement decidedly in a low typhoid State.and getting progressively more $\&$ more advanced, died on the 18th. The Leg became inflamed \& the Matter foetid in the Extreme seemed to form all around the Fracture."

Case 55. R. H. male aged 30 admitted with compound dislocation "of ye. Thumb admitted July 12 under Mr Hey. In a fit of intoxication the preceeding [sic] day he managed to produce the Above Accident in the 1st. Joint,-came immediately, had it easily reduced but returned \& wived [sic] about till next day, 12th. when having come to his senses he thought it best to remain. The Thumb \& Hand were inflamed, \& very painful, inflamation [sic] extending upwards along inside of Arm-rested in Bed \& had Catapl. applied to hand \& thumb to Arm hoping supportive would soon come on to produce an alleviation of symptoms-he contind. getting rather worse, inflamation [sic] be extending on \& very feverish till Saturday, July 16 when a hardness with extreme tenderness \& pain particularly on pressure was discovered in ye. fore pt. of ye. Arm just above Wrist Joint, had Hirud: xviii [leeches] applied \& Catapl.-Wash contd. all along Arm to Axilla being very much inflamed, \& painful, high degree of fever-...-On Monday July 19 Inflan. still continuing but little relivd. had 10 more Hirud. applied,-it now felt as if matter was forming deep seated, \& on 21 being very distinct indeed was opened,-this gave great relief-\& Fever begun to decline on Saturday 24-another opening made near the former which gave issue to a large discharge \& produced great relief. 29. an abscess opened on ye. thumb which appeared destroyed in its Joint by the severity of the Infin.By Monday August 2nd. all Fever \& inflamation [sic] had disappeared, abscess of Arm nearly well \& Joint of Thumb being quite destroyed, the end of ye. Bones grating together so it was removed. He afterwards did quite well \& was discharged in about 10 days."

Case 56. J. W. male aged 52 with irreducible femoral hernia admitted "at $10 \mathrm{pm}$ on Aug. 11th. under Mr. S. - has had rupture 3 yrs which he thought was first induced by a lift.-as large as a split walnut, never went clean back, perhaps 1 left behind. Early last Morng. fell with some force upon his Back. Hernia increased gt. which it not done for 3 or 4 days-began to be red \& painful-Kept getting rather larger, more painful \& somewhat redder-In the course Tuesday he sent in Quack who much to do \& a good deal of pain put it up,- -at least he thinks nearly as much as usually has gone-before was now returned, it was now a good deal inflamed so this pn. 
ordered some Leeches \& cold Wash to the part same afternoon, next Morning Wednesday it came down again, he sent to his Dr. who made a long \& painful trial to reduce it but did no good.-Sent for a Surgeon who attempted a little but equally ineffectually, administered Enema Tabac: [Tobacco enema, made by infusing the leaves in boiling water; was considered useful in strangulated hernia, obstinate constipation, and retention of urine $\left.{ }^{11}\right]$ wh. produced some sickness during he tried but in Vain-he was now bled-On Tuesday had taken a pill \& a powder the next (Thurs) Morning which had preceded plenty of Enemations. He was now brought to Infy. It appeared at first merely an enlarged Gland about size of an Apple much inflamed \& rather painful, very hard-had had no pain elsewhere in Body, no sickness or vomiting had little Fever-Baln. tepd. Vino frigid. slight attempt at reduction, Bowels kept open \& cold applications contd. with rest in Bed, Low diet \& Sulphur about a fortnight, during which time Hernia gradually \& almost entirely disappeared. -quite as small as ever-discharged Cured."

Case 57. W. C. male [no age given] with strangulated scrotal congenital hernia admitted on 28 July "under Mr. Ch. on Merc. 10 pm.- had been down an hour Łp. 10 Baln. tepid: after a fair trial of manuel [sic] efforts-reduction attempted in Bath but ineffectually. . . . Enema.-Hernia hard, -no stool. Jovis 7 o'Clock amnight restless, hernia harder. Baln. tepid. . . . 10 pm a quiet evening vomiting occasionally. No Stool more. Enema. Cont. Frigid. App. Hernia rather softer \& less since Morning. Veneris 7 am quiet \& comfortable. Vomited several times in Night, no stool, fairly hotish [sic]. Cont. Enema etc 11 o'Cl Stool 11 p.m Stool-a midling [sic] day.-He is as before. Saturn: 7 am good Night, no more Stools. vomited less frequently, doing very well in Appace. Solis 9 am had a bad Night in Vomiting. much exhausted and died this Morning. Dissection."

\section{DISCUSSION}

Operations. A list of eighty-nine operations carried out by Messrs Chorley, Hey, and Smith is shown in Appendix II, but this does not include those performed on patients who had accidents (Appendix III) and those already described in 'Brief notes of the treatment of some particular accidents' (pp. 60-83).

The variety of operations is necessarily limited, as internal operations were almost unknown before the days of anaesthesia, except for lithotomy. The commonest operation was amputation and although twenty amputations of the leg are mentioned we must add another two from the 'Brief notes'. Four amputations of the arm took place with the addition of three more from 'Brief notes'. Apart from the patients with accidental injury, several had amputation for tuberculous joints and ten had bones removed because they were "carious", some of which may have been tuberculous. Couching of the eye for cataract was performed twelve times, and tumours removed from the breast, testis, and lip. In 'Brief notes of some cases after operation' (not given in detail here) the removal of a cancerous tumour of the tongue in a woman aged sixty-nine is described. It was carried out by ligation and after a month the tumour sloughed away with, apparently, a good result. Hare-lip was

11 Anning, op. cit., note 3 above. 


\section{S. T. Anning}

operated on seven times (repeated in some cases) and occasionally naevi were removed. Operation for strangulated hernia is mentioned both in the list of operations and in the 'Brief notes', but details of technique are not given.

In the Infirmary Rules of 1767 (Rule XLIV) we read that "no Child under Six Years of Age, (except in extraordinary Cases, as Fractures, or where Cutting for the Stone, or any other Operation is required) is admissible." ${ }^{12}$ As we shall see, many such were admitted for fractures but of the five patients who underwent Lithotomia (three from the list of operations and two "Accidents") four were infants. Urinary calculi in children were much more common in the eighteenth and nineteenth centuries. Although East Anglia enjoyed an unenviable reputation for this condition, it is worthy of note that Batty Shaw found that in 1822 about a third of such cases in Norfolk were under ten years of age. ${ }^{13}$ Other operations, all uncommon, were for phymosis, hydrocoele, fatty tumours, fistula lachrymalis, and fistula in ano.

Accidents. Of the group entitled "Accidents etc." (Appendix III) the majority relate to fractures, and of the 226 patients reported in this Appendix only fourteen were not fractured or dislocated. It is of note that twenty-seven of the fractures out of a total of 198 were in children of five years or less, and of these seventeen were three years or under. The suspicion must arise that they were "battered".

In the age group six to sixteen years inclusive, there were seventy-seven fractures, of which twenty were in girls. Allowing for the usual injuries of childhood, these are considerable figures and raise the question of child labour. In 1840 the House of Commons set up a commission to inquire into the state of children employed in the mines and manufacturies. The four Commissioners (Thomas Tooke, T. Southwood Smith, Leonard Horner, and Robert J. Saunders) reported inter alia "That instances occur in which Children begin to work as early as three and four years of age; not unfrequently at five, and between five and six; while, in general, regular employment commences between seven and eight; the great majority of the Children having begun to work before they are nine years old .... That in a very large proportion of these Trades and Manufactures female Children are employed equally with boys, and at the same tender ages: in some indeed the number of girls exceeds that of boys. ..."

It has not been found possible to assess the number of children employed in industry in Leeds during the period in question, but we do know that in Marshall's Flax Mill in 1820 the labour force was 1,000 and was the same in 1830 when there were five boys under thirteen, and eighty-five boys and 272 girls aged thirteen to seventeen. ${ }^{14}$ Comparable figures are likely to have applied to many of the factories in Leeds at the time. We have accounts of nine accidents from machinery in the 'Brief notes' of fifty-seven patients, and it seems likely that a number of the fractures in Appendix III occurring in the six to sixteen age group were industrial.

12 Anning, op. cit., note 2 above, vol. 1, p. 81.

18 A. Batty Shaw, 'The Norwich school of lithotomy', Med. Hist., 1970, 14: 221-259, p. 241.

14 W. G. Rimmer, Marshalls of Leeds, flax-spinners 1788-1886, Cambridge University Press, 1960, pp. 308 and 316. 
The practice of surgery in Leeds 1823-1824

Coal-mining was another occupation in which accidents were common. By the 1820 s the risk of explosions was much reduced in the better managed pits as ventilation was more efficient and safety-lamps were used. Unfortunately, some ill-disciplined miners, being on piece work, removed the gauze in order to see better and so increase their productivity. However, the risk of injury from falls of coal from the roof of the seams was considerable, and though we have only two examples among the 'Brief notes', some of the accidents listed in Appendix III must have been in coalminers. It must be remembered also that in mines child-labour was usual. In Yorkshire it was common practice to start children in the pits underground at the age of six years, both boys and girls. ${ }^{15}$

There are five injuries mentioned in the 'Brief notes' which seem to have occurred among quarry-men. Thackrah ${ }^{16}$ remarks that "when they escape the severe accidents so common in their employ they often attain considerable age." The examples given in 'Brief notes' were all in adults.

Among other patients described in the 'Notes' are five with retention of urine, and there is one among the accident cases (Appendix III). Two of these probably had enlarged prostates, one had a hydatid cyst, and the other three had strictures, no doubt post-gonorrhoeal.

In considering the result of treatment of the fifty-seven patients reported in 'Brief notes' we see that seventeen died. This was usually the result of infection, from which twenty-six patients in this series suffered.

\section{SUMMARY}

The contents of a leather-bound manuscript notebook dated March 1823 to August 1824 is described. It was probably written by an apothecary and gives a list of operations carried out at the General Infirmary at Leeds during this period by three surgeons on the staff of the hospital: Messrs. Thomas Chorley, William Hey the second, and Samuel Smith. It also gives a list of accident cases treated and case notes of fifty-six patients suffering from accidents. There are also some brief notes of patients after operation and the implications of accidents occurring among children employed in mines and factories are discussed.

\section{APPENDIX I: PLACES OF ORIGIN OF PATIENTS MENTIONED IN THE NOTEBOOK}

Place of Origin

Leeds*

Bradford area

\section{Approximate Distance (in miles)}

*Including: Armley Beeston, Bramley, Burley, Chapeltown, Farnley, Holbeck. Horsforth, Hunslet, Kirkstall, Potternewton, Roundhay, Seacroft, Woodhouse, Wortley, Wyther.

15 G. Mee, Aristocratic enterprise: the Fitzwilliam Industrial Undertakings 1795-1857, Glasgow, Blackie, 1975, p. 132ff.

16 Charles Turner Thackrah, The effects of arts, trades and professions . . on health and longevity, London, Longman, 1832, p. 18. 


\section{S. T. Anning}

$\begin{array}{lcc}\begin{array}{l}\text { APPENDIX I: PLACES OF ORIGIN OF PATIENTS-Continued } \\ \text { Place of Origin }\end{array} & \begin{array}{c}\text { Approximate Distance } \\ \text { (in miles) }\end{array} & \text { Number of Patients } \\ \text { Pudsey, Stanningley } & 6 & \\ \text { Huddersfield area } & 15 & 9 \\ \text { Morley, Dewsbury, Elland } & 9 & 8 \\ \text { Bramham, Tadcaster, York } & 24 & 7 \\ \text { Halifax area } & 15 & 6 \\ \text { Harrogate area } & 17 & 6 \\ \text { Pontefract area } & 23 & 5 \\ \text { Selby area, Kippax } & 21 & 5 \\ \text { Wakefield area } & 9 & 4 \\ \text { Batley } & 7 & 4 \\ \text { Eccup, Harewood } & 9 & 3 \\ \text { Pateley Bridge } & 39 & 2 \\ \text { Barnsley area } & 19 & 2 \\ \text { Wetherby area } & 13 & 2 \\ \text { Bingley, Shipley } & 11 & 2 \\ \text { Skipton } & 25 & 2 \\ \text { Rotherham } & 29 & 2 \\ \text { Otley } & 11 & 1 \\ \text { Gargrave } & 40 & 1 \\ \text { Grassington } & 33 & 1 \\ \text { Haworth } & 19 & 1 \\ \text { Miscellaneous } & - & 1 \\ & & 4 \\ & & 355\end{array}$

APPENDIX II: LIST OF OPERATIONS

Patient Sex Age Disease and Operation Surgeon Date

1823

1. W. E. M 60 Cancer of lip excised

Hey 20 March

2. J. B. M 23 Caries and ulcers of leg and foot.

$$
\text { Amputation Smith } 30 \text { April }
$$

3. I. C. F 22 Removal of small tumour left mamma;

$$
2 \text { or } 3 \text { attacks of erysipelas }
$$

Smith 30 April

4. N. G. F 19 Operation for fistula lachrymalis

Chorley 5 May

5. A. M. M 48 Removal of enlarged testis

Chorley 5 May

6. J. F. F 21 Three hard tumours removed left mamma

Hey

13 May

7. M. S. F 48 Small fatty tumour removed left axilla

Chorley 14 May

8. J. S. M 19 Diseased skin removed from sternum

Chorley 14 May

9. D. P. M 4 Lithotomis

Chorley 8 April 


\section{APPENDIX II: LIST OF OPERATIONS-Continued}

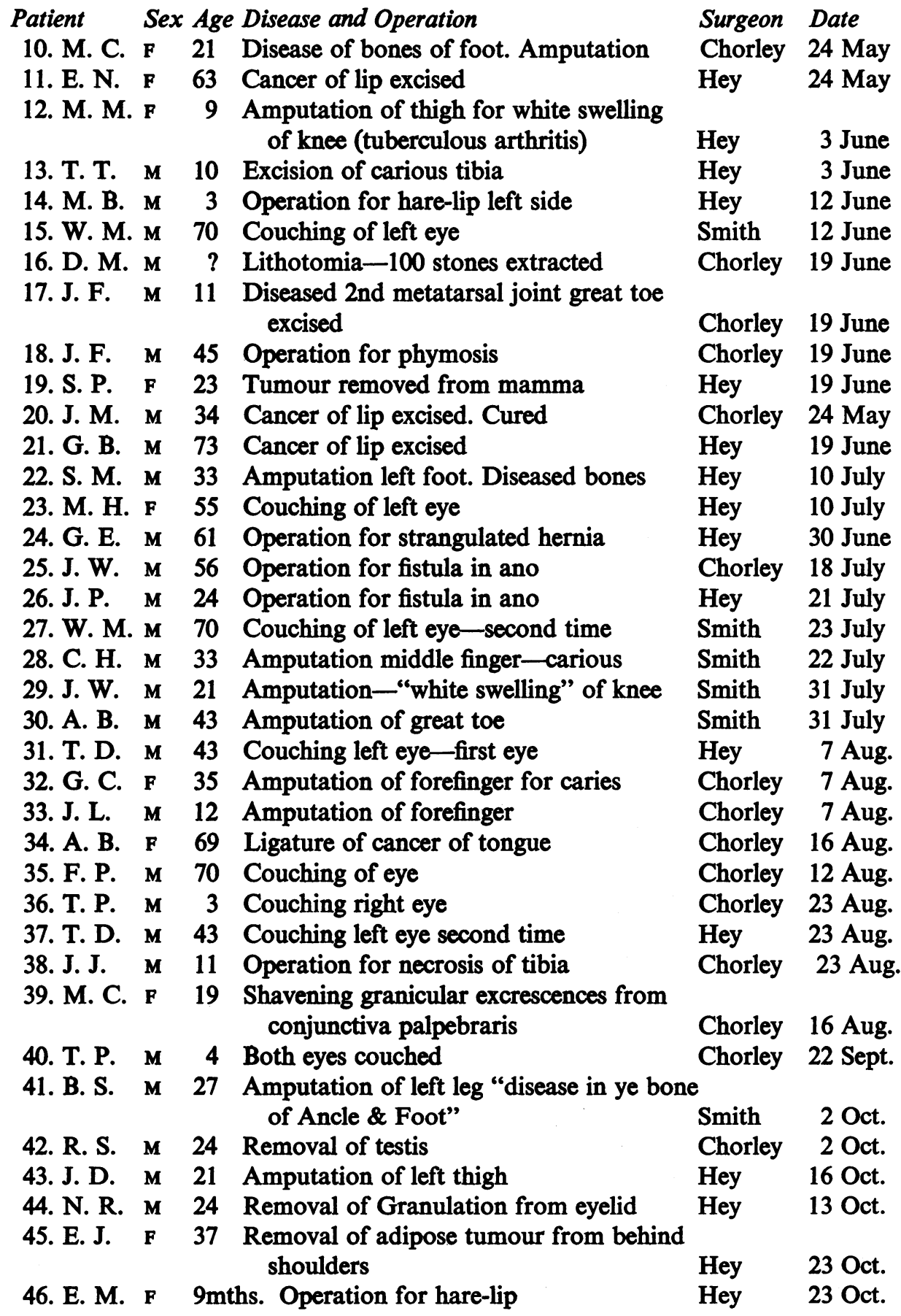




\section{S. T. Anning}

\section{APPENDIX II: LIST OF OPERATIONS-Continued}

Patient Sex Age Disease and Operation

47. J. H. $M 59$ Operation for fistula in ano

48. W. C. M 10 Operation for hare-lip

49. J. B. M 50 Amputation of forearm

50. J. S. M 10 Removal of first metatarsal and toe for caries

51. J. A. M 1 Removal of naevus maternus* from over shoulder

52. W. B. M 47 Couching both eyes

53. W. B. M 47 Operations above repeated

54. W. C. M 35 Couching both eyes

55. C. W. F 10 mths. Removal of naevus maternus from upper lip.*

56. A. B. F 32 Amputation of right leg

57. A. B. F 21 Amputation of right leg

58. D. M. M 8 Right arm amputated for compound fracture of radius and ulna

59. T. G. M 37 Injection for hydrocoele

60. J. P. M 50 Injection for hydrocoele

61. J.W. F

62. T. P. M

63. J. S. M

64. J. M. M

65. J. S. M

66. S. H. F

67. J. S. M

68. J. H. M

69. J. F. $M$

70. G. G. $M$

71. S. R. $M$

72. M. L. F

73. J. W. $M$

74. J. E. M

75. T. P. F

76. H. H. M

77. L. B. $F$

78. J. P. M

79. S. W. M
Operation for necrosis of tibia

20 Lithotomia

20 Removal of great toes for caries

20 Operation for phymosis

11 Amputation of thigh

10 Operation for hare-lip

Amputation of right arm

18 Amputation of left leg

11 Amputation of right leg

23 Amputation of left leg

19 Exterpolation of cyst from within eyelid

19 Scrofulous knee joint amputated

44 Amputation of right foot

49 Amputation of left leg below knee

55 Removal of tumour of hand

3 Second hare-lip operation

Amputation of finger joint

26 Amputation of part of foot

3 First hare-lip operation
Surgeon Date

Chorley 27 Nov.

Chorley 27 Nov.

Smith 4 Dec.

Smith 11 Dec.

Smith 11 Dec.

Hey 27 Dec.

1824

Hey 17 Jan.

Smith 12 Jan.

Hey 15 Jan.

Hey 17 Jan.

Chorley 17 Jan.

Smith 18 Jan.

Hey $13 \mathrm{Feb}$.

Hey 13 Feb.

Chorley 1 March

Hey 2 March

Hey 12 Feb.

Chorley 7 March

Smith 10 March

Smith 10 March

Smith 23 March

Smith 17 March

Smith 17 April

Smith 6 May

Smith 6 May

Chorley 23 April

Hey 7 May

Chorley 17 May

Chorley 17 May

Chorley 17 May

Hey 10 May

Hey 10 May

Hey 17 May

*Probably capillary haemangionma-"Strawberry mark". See: J. Quincy, Lexicon physico-medicum, London, E. Bell, 1722, 2nd ed., p. 296, "those Marks as are made upon the Foetus, by the Imagination of the Mother, in longing for any thing." 


\section{APPENDIX II: LIST OF OPERATIONS-Continued}

Patient Sex Age Disease and Operation

80. J. K. M Amputation of right thigh

81. J. W. M 14 Amputation of right thigh

82. S. I. F 55 Operation for fistula lachrymalis

83. F. M. F 8 Operation for fistula lachrymalis

84. R.K. M 14 Removal of fungus from gingiva

85. S. W. M 3 Second hare-lip operation

86. J. D. M 10 Amputation of arm

87. J. H. M 15 Amputation of left leg-casualty

88. J. P. M

89. J. P. M
Couching right eye

Couching right eye second time
Surgeon Date

Hey 17 May

Chorley 1 July

Chorley 1 July

Chorley 1 July

Chorley 1 July

Chorley $1 \mathrm{July}$

Chorley 30 July

Hey 5 July

Hey 1 Aug.

Hey 18 Aug.

\section{APPENDIX III: ACCIDENTS, etc.}

\section{Patient Sex Age Injury}

Surgeon Date

1823

1. D. O. M 57 Simple fracture of radius. Cured

2. J. P. M 55 Compound fracture of tibia

3. E. T. F 3 Simple fracture of tibia. Cured

4. R. G. M 10 Simple fracture of thigh. Cured

5. J. W. M 26 Simple fracture of thigh

6. A. B. M 5 Simple fracture of radius

7. S. R. M 21 Simple fracture of thigh

8. G. E. M 54 Strangulated femoral hernia reduced in tepid bath

9. W. S. M 30 Simple fracture of fibula

10. T. B. M 8 Simple fracture of thigh

11. E. I. F 3wks. Fractured clavicle

12. W. P. M 3 Simple fracture of thigh

13. T. S. M 24 Fracture of lower jaw

14. E. P. M 2 Fractured clavicle

15. R. B. M 7 Simple fracture of radius

16. W. T. M 11 Simple fracture of thigh

17. R. S. M 11 Simple fracture of external condyle of right humerus

18. Z. R. M 4 Fracture of clavicles

19. J. G. M 47 Fractured clavicle

20. J. P. M 11 Compound fracture of legs-died (see Brief notes, case 2)

21. J. V. M 14 Fractured clavicle

22. J. C. M 40 Fractured radius

23. W. I. M 10 Simple fracture of internal condyle of humerus
Smith 24 March

Smith 27 March

Hey 5 April

Hey 10 April

Smith 12 April

Smith 14 April

Chorley 25 April

Smith 4 May

Chorley 13 May

Chorley 8 May

Chorley 12 May

Hey 21 May

Smith 24 May

Smith 25 May

Smith 24 May

Smith 26 May

Smith 27 May

Smith 28 May

Smith 28 May

Chorley 31 May

Chorley 5 June

Chorley 5 June

Chorley 6 June 


\section{S. T. Anning}

APPENDIX III: ACCIDENTS, etc.-Continued

Patient Sex Age Injury

24. J. W. M 6 Simple fracture of internal condyle of humerus

25. A. M. F 16 Compound fracture of tibia (see Brief notes, case 3)

26. S. W. F 50 Simple fracture of radius

27. L. G. F 12 Simple fracture of radius

28. I. E. $M 9$ Simple fracture of radius

29. S. H. M 1 Simple fracture of thigh

30. E. P. F 3 Fractured clavicle

31. J. C. M 1 Fracture of thigh

32. W. F. M 5 Fracture of radius

33. J. T. M 12 Simple fracture of leg

34. J. B. $M \quad 30$ Compound fracture of thigh (see Brief notes, case 4)

35. E. P. F 33 Fungus haematodes left leg (died)

36. J. L. M 62 Retention of urine

37. J. T. M 12 Fracture of radius

38. Z. B. F 63 Fracture of radius

39. W. L. M 13 Fracture of radius

40. G. E. M 61 Strangulated femoral hernia

41. T. K. M 20 Simple fracture of radius and ulna (see Brief notes, case 14)

42. I. W. $F \quad 8$ Fracture of radius

43. G. M. M 24 Simple fracture of fibula

44. J. B. $M$

45. -. R. M

46. J. L. $M$

47. W. R. $M$

48. A. P. $M$

49. B. V. F

50. P. G. F

51. S. M. M

52. J. F. M

53. J. B. $M$

54. T. W. $M$

55. T. G. $M$

56 J. W. M

57. D. D. $M$

58. D. G. $M$

38 Dislocated shoulder-reduced

Old irreducible hernia

23 Concussion of brain (see Brief notes, case 6)

19 Fracture of clavicle

54 Fracture of radius

13 Injury of fingers (see Brie
21 Simple fracture of thigh

6 Simple fracture of thigh (see Brief notes, case 18)

4 Fracture of radius
Surgeon Date

Hey

7 June

Hey 7 June

Hey 7 June

Hey 7 June

Hey 9 June

Hey 11 June

Hey 12 June

Smith 17 June

Smith 18 June

Smith 18 June

Smith 20 June

Chorley 13 May

Chorley 16 May

Chorley 27 June

Chorley 27 June

Hey 29 June

Hey 29 June

Hey 2 July

Hey 3 July

Hey 3 July

Hey 4 July

Chorley 2 July

24 Fracture of fibula (see Brief notes, case 13) Smith 7 July

Smith 9 July

Chorley 12 July

Chorley 16 July

Chorley 18 July

Smith 9 July

(see Brief notes, case 15) Hey $18 \mathrm{July}$

21 Injury of foot (see Brief notes, case 16) Hey $18 \mathrm{July}$

52 Fracture of acromion process of scapula Hey $19 \mathrm{July}$

9 Fracture of radius Hey 22 July

6 Fracture of radius Hey 20 July

Smith 28 July

Smith 30 July 
APPENDIX III: ACCIDENTS, etc.-Continued

Patient Sex Age Injury

59. R. W. M 4 Fracture of humerus

60. M. H. F 6 Fracture of humerus

61. J. L. M 16 Simple fracture of cervix femoris (see Brief notes, case 19)

62. B. W. M 19 Compound fracture of tibia (see Brief notes, case 20)

63. H. M. M 57 Injury of hand and fingers (See Brief notes, case 21)

64. W. H. M 11 Fracture of arm

65. J. B. M 36 Injury of spine (see Brief notes, case 22)

66. M. H. F 60 Fracture of clavicle

67. R. B. M 18 Fracture of patella (see Brief notes, case 23)

68. J. T. M 32 Compound fracture of humerus

69. A. D. F 10 Compound fracture of leg (see Brief notes, case 25)

70. M. N. M 20 Severe injury left arm (see Brief notes, case 26)

71. B. L. M 17 Simple fracture of left thigh (see Brief notes, case 27)

72. E. C. $F \quad 6$ Fracture of radius and ulna

73. J. C. M 53 Fracture of clavicle

74. J. S. M

75. E. S.

76. J. B. M 40

77. M. T. F

78. S. S. M 56

Injury of hand (see Brief notes, case 28)

3 Simple fracture of external condyle of humerus

Fracture of radius

Simple fracture of ulna

Compound dislocation of tibia with fracture (see Brief notes, case 29)

79. J. G. M 53 Strangulated inguinal hernia

80. J. C. M 24 Wound of ankle

81. H. F. M 11 Fracture of clavicle

82. J. F. $M \quad 11$ Injured fingers

83. J. R. M 12 Dislocation of left elbow

84. T. S. M 15 Fracture of tip of clavicle

85. E. T. F 15 External dislocation of patella

86. B. B. F 8 Fracture of clavicle

87. M. B. F 11 Fracture of clavicle

88. M. B. M 33 Fracture of radius

89. R. T. M 52 Simple dislocation of tibia and

$$
\text { fracture of fibula }
$$

90. W. P. M 25 Simple fracture of radius
Surgeon Date

Chorley 1 Aug.

Chorley 2 Aug.

Chorley 3 Aug.

Chorley 4 Aug.

Chorley 6 Aug.

Chorley 7 Aug.

Smith 14 Aug.

Hey 14 Aug.

Smith 18 Aug.

Smith 18 Aug.

Chorley 22 Aug.

Chorley 23 Aug.

Chorley 25 Aug.

Hey 30 Aug.

Hey 2 Sept

Hey 2 Sept.

Hey 4 Sept.

Hey 4 Sept.

Hey 7 Sept.

Hey 6 Sept.

Hey 6 Sept.

Hey 4 Sept.

Hey 7 Sept.

Hey 7 Sept.

Smith 11 Sept.

Chorley 18 Sept.

Chorley 18 Sept.

Chorley 19 Sept.

Hey $20 \mathrm{Sept}$.

Hey 21 Sept.

Smith 28 Sept.

Smith 28 Sept. 


\section{S. T. Anning}

APPENDIX III: ACCIDENTS, etc.-Continued

\begin{tabular}{|c|c|c|c|c|c|}
\hline Patient & & $A g$ & Injury & Surgeon & Date \\
\hline 1. A. S. & $\mathbf{M}$ & 45 & Simple fracture of fibula & Smith & 1 Oct. \\
\hline 92. J. W. & $\mathbf{M}$ & 7 & Fracture of external condyle of humerus & Chorley & 4 Oct. \\
\hline 93. W. B. & $\mathbf{M}$ & 20 & Fracture of clavicle & Chorley & 6 Oct. \\
\hline 94. J. L. & $\mathbf{M}$ & 9 & Dislocation of ulna & Chorley & 8 Oct. \\
\hline 95. E. H. & $\mathbf{M}$ & 16 & Simple fracture of leg & Smith & 19 Oct. \\
\hline 96. J. W. & $\mathbf{M}$ & 23 & Simple fracture of radius and ulna & Smith & 19 Oct. \\
\hline 97. J. L. & $\mathbf{M}$ & 15 & Fracture of clavicle & Chorley & 26 Oct. \\
\hline 98. J. L. & $\mathbf{M}$ & 27 & Fracture of arm & Chorley & 25 Oct. \\
\hline 99. T. L. & $\mathbf{M}$ & 13 & Fracture of arm & Chorley & 28 Oct. \\
\hline 100. W. S. & $\mathbf{M}$ & 1 & Fracture o & Hey & $6 \mathrm{Nov}$ \\
\hline 101. T. T. & $\mathbf{M}$ & 37 & f metacarpal & Hey & 7 No \\
\hline 102. T. H. & $\mathbf{M}$ & 14 & Fract & Hey & 13 No \\
\hline 103. T. D. & $\mathbf{M}$ & 23 & Simple fract & Hey & No \\
\hline 104. S. M. & $\mathbf{M}$ & 12 & Simple fracture of humerus & Smith & $10 \mathrm{Nor}$ \\
\hline N.S. & $\mathbf{M}$ & 13 & Simple fracture of leg & Smith & 10 Nov \\
\hline 6. M. B. & $\mathbf{F}$ & 10 & Simple fract & Chorley & 18 No \\
\hline 7. & $\mathbf{M}$ & 15 & $\begin{array}{l}\text { Compound fracture of humerus, simple } \\
\text { fracture of radius and ulna (see }\end{array}$ & & \\
\hline 08. J. C. & $\mathbf{M}$ & 21 & Fracture 0 & Hey & $22 \mathrm{Nov}$ \\
\hline . S. & $\mathbf{M}$ & 6 & Frac & Hey & $25 \mathrm{Nov}$ \\
\hline 10. C. P. & $\mathbf{F}$ & 6 & Fract & Hey & $26 \mathrm{Nov}$ \\
\hline 111. W. B. & $\mathbf{M}$ & 43 & Dislo & Hey & 26 No \\
\hline 112. G. R. & $\mathbf{M}$ & 10 & Fractı & Smith & 29 Nor \\
\hline 113. D. C. & $\mathbf{M}$ & 40 & Compound fracture of forearm & Smith & 2 Dec \\
\hline & $\mathbf{F}$ & 8 & $\begin{array}{l}\text { Dislocation of head of radius with } \\
\text { fracture of ulna }\end{array}$ & Smith & 1 Dec. \\
\hline 115. B. S. & $\mathbf{M}$ & 17 & Fractur & Chorley & 6 Dec. \\
\hline N. H. & $\mathbf{M}$ & 21 & Frac & Hey & $15 \mathrm{Dec}$ \\
\hline 17. W. G. & $\mathbf{M}$ & 13 & Fracture of leg & Hey & 17 Dec \\
\hline 18. G. S. & $\mathbf{M}$ & 56 & Strangulated hernia reduced in tepid bath & Hey & $18 \mathrm{Dec}$ \\
\hline 19. S. P. & $\mathbf{M}$ & 50 & Fracture & Hey & 19 Dec. \\
\hline 120. D. T. & $\mathbf{M}$ & 20 & Fractu & Smith & 23 Dec. \\
\hline 121. B. E. & $\mathbf{M}$ & 17 & erus & Smith & $23 \mathrm{Dec}$ \\
\hline 122. G. S. & $\mathbf{M}$ & 17 & Fract & Smith & 23 Dec \\
\hline 23. J. H. & $\mathbf{M}$ & 19 & humerus & Smith & 24 Dec. \\
\hline 24. M. B. & $\mathbf{M}$ & 10 & Fracture of leg & Smith & 25 Dec. \\
\hline 125. J. B. & $\mathbf{M}$ & 26 & Fracture of finger & Smith & 25 Dec. \\
\hline 126. J. L. & $\mathbf{M}$ & 20 & Fracture of clavicle & Chorley & 30 Dec. \\
\hline 127. H. & $\mathbf{F}$ & 11 & $\begin{array}{l}\text { Compound fracture of left tibia and fibula } \\
\text { with simple fracture of right tibia and } \\
\text { fibula (see Brief notes, case 31) }\end{array}$ & 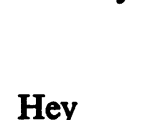 & \\
\hline
\end{tabular}


APPENDIX III: ACCIDENTS, etc.-Continued

Patient Sex Age Injury

128. W. G. M 22 Dislocated clavicle

Surgeon Date

129. W. G. M 3 Fracture of jaw

130. J. C. M 13 Fracture of thumb

131. T. A. M 79 Fracture of neck of femur

132. B. F. F 1 Fracture of clavicle

133. M. S. F 43 Compound fracture of tibia and fibula (see Brief notes, case 32)

134. J. H. M 10 Fracture of arm

135. J. R. F 13 Fracture of left arm and leg

136. J. R. M 6 Fracture of arm

137. A. W. F 3 Fracture of clavicle

138. J. W. M 54 Fracture of clavicle

139. J. W. M 11 Dislocated elbow

140. J. D. M 11 Compound fracture of ulna (see Brief notes, case 38)

141. D. M. M 52 Compound fracture of arm

142. T. B. $M \quad 8$ Fracture of clavicle

143. M. L. F 74 Fracture of radius

144. G. H. M 51 Retention of urine

(see Brief notes, case 33)

145. J. W. M 34 Fracture of radius

146. T. E. M 15 Fracture of radius

147. C. B. M 17 Fracture of scapula

148. R. T. M 17 Dislocation of clavicle

149. T. T. M 23 Fracture of clavicle

150. F. H. M 5 Fracture of clavicle

151. W. W. M 24 Compound fracture of radius and ulna (see Brief notes, case 43)

152. J. L. M 36 Fracture of acromion

153. R. S. M 25 Dislocated shoulder

154. C. B. M 35 Fracture of skull (see Brief notes, case 34)

155. M. H. F

6 Fracture of clavicle

156. J. T. M

157. T. T. $M$

158. H. T. $M$

5 Fracture of clavicle

13 Fracture of tibia

159. G. H. $M$

6 Fracture of clavicle

160. W. C. $M$

25 Strangulated scrotal hernia

161. W. E. $M$

2 Strangulated hernia

162. W. H. M

9 Fracture of clavicle

163. J. B. $M$

29 Fracture of tibia

164. I. W. M

14 Fracture of tibia

165. W. F. $M$

24 Fracture of fibula

3 Fracture of tibia (see Brief notes, case 47)

Hey

3 Jan.

Hey $6 \mathrm{Jan}$.

Smith 12 Jan.

Smith 14 Jan.

Smith 15 Jan.

Chorley 19 Jan.

Chorley $20 \mathrm{Jan}$.

Chorley $20 \mathrm{Jan}$.

Chorley $20 \mathrm{Jan}$.

Hey 27 Jan.

Smith 30 Jan.

Smith 1 Feb.

Smith $5 \mathrm{Feb}$.

Smith 6 Feb.

Chorley $9 \mathrm{Feb}$.

Chorley $10 \mathrm{Feb}$.

Chorley 10 Feb.

Hey $13 \mathrm{Feb}$.

Hey 16 Feb.

Smith 24 Feb.

Smith 25 Feb.

Hey 5 March

Hey 7 March

Hey 10 March

Hey 12 March

Chorley 23 March

Chorley 26 March

Smith 4 April

Chorley 10 April

Chorley 10 April

Chorley 12 April

Chorley 13 April

Chorley 16 April

Hey 18 April

Smith 30 April

Hey 16 April

Hey 16 April

Hey 21 April 


\section{S. T Anning}

APPENDIX III: ACCIDENTS, etc.-Continued

Patient Sex Age Injury

Surgeon Date

166. T. N. M 56 Fracture of thigh (see Brief notes, case 48) Chorley 1 May

167. W. B. M 12 Fracture of tibia Chorley 4 May

168. W. N. M 35 Retention of urine (Brief notes, case 36) Chorley 5 May

169. W. R. M 32 Fracture of clavicle Chorley 5 May

170. J. B. M 29 Fracture of clavicle Chorley 1 May

171. M. W. F 2 Fracture of thigh Smith 7 March

172. W. W. M 20 Fracture of radius

173. F. C. F 4 Fracture of radius

174. S. C. M 15 Fracture of jaw

175. J. E. M $4 \frac{1}{2}$ Compound fracture of leg

176. J. S. M $2 \frac{1}{2}$ Calculus in urethra-cut out

177. J. L. M 4 Calculus in urethra-cut out

178. J. C. M 32 Compound fracture of thumb

Smith 25 April

Hey 8 May

Hey 11 May

Hey 11 May

Smith 15 May

Smith 17 May

179. T. N. M 41 Fracture of os calcis

Smith 16 May

180. S. R. M 61 Fracture of thigh and contusion of knee

181. W. H. M 14 Fracture of tibia

182. H. T. M 16 Lacerated arm-amputation

183. J. G. M 12 Fracture of humerus

184. J. I. M 32 Contusion and compression of spine (see Brief notes, case 40 )

185. C. N. M 37 Injury of body (see Brief notes, case 41)

186. A. W. M 16 Inflammation of leg (erysipelatous) (see Brief notes, case 42)

187. J. M. M 14 Inflammation of thigh

188. M. H. F 10 Fracture of ulna

189. M. J. F 30 Fracture of radius

190. J. C. M 11 Fracture of radius

191. T. P. M 50 Fracture of thigh

192. A. C. F 80 Fracture of humerus

193. J. K. M 32 Compound fracture of tibia (see Brief notes, case 54)

194. J. P. M 7 Compound fracture of tibia

195. J. W. M 20 Fracture of fibula

196. B. D. M 16 Fracture of forearm

197. T. E. M 22 Dislocated elbow

198. J. G. M 12 Dislocated elbow

199. E. R. M 19 Fracture of skull

200. R. T. M 42 Simple dislocation of knee (see Brief notes, case 53)

201. C. D. F 77 Fracture of humerus

202. E. N. F 8 Fracture of radius and contusions

Smith 19 May

Smith 20 May

Smith 21 May

Smith 18 May

Chorley 27 May

Hey 10 May

Chorley 6 May

Hey 2 April

Hey 23 April

Hey 4 June

Hey 4 June

Smith 5 June

Smith 8 June

Smith 10 June

Smith 8 June

Smith 10 June

Smith 11 June

Chorley 4 July

Hey 14 July

Smith 20 July

Chorley 8 July

Chorley 6 July

Hey 12 July

Hey 12 July 
APPENDIX III: ACCIDENTS, etc.-Continued

Patient Sex Age Injury

203. T. W. F 14 Fracture of humerus

204. R. H. M 30 Compound dislocation of thumb (see Brief notes, case 55)

205. J. D. M 21 Fracture of tibia and contusions

206. W. O. M 9 Simple fracture of both thighs

207. J. N. M 40 Compound fracture of tibia (see Brief notes, case 50)

208. B. R. ?M 6 Fracture of humerus

209. S. H. M 26 Retention of urine (see Brief notes, case 51)

210. M. K. F 6 Fracture of radius

211. M. G. F 40 Dislocated finger

212. T. S. M 32 Compound fracture of tibia

213. J. H. M 42 Dislocated finger

214. J. W. M 52 Irreducible femoral hernia (see Brief notes, case 56)

215. M. S. $F \quad 6$ Fracture of arm

216. T. C. M 40 Fracture of tibia

217. G. C. M 30 Fracture of tibia

218. J. W. M 33 Fracture of tibia

219. G. W. M 8 Fracture of radius

220. E. T. F 64 Dislocated shoulder

221. J. R. M 36 Fracture of tibia

222. -. W. ?M 14 Dislocated elbow

223. M. B. F 1 $1 \frac{1}{2}$ Simple fracture of thigh

224. J. C. M 36 Compound fracture of radius and ulna

225. J. W. M 26 Fracture of leg

226. -. W. ?M 2 Strangulated congenital hernia
Surgeon Date

Hey 13 July

Hey 13 July

Hey 16 July

Smith 26 June

Smith 16 July

Smith 19 July

Smith 12 July

Hey 3 Aug.

Hey 3 Aug.

Hey 4 Aug.

Smith 9 Aug.

Smith 11 Aug.

Smith 11 Aug.

Chorley 17 Aug.

Chorley 18 Aug.

Chorley 13 Aug.

Hey 21 Aug.

Hey 30 Aug.

Smith 30 Aug.

Smith 1 Sept.

Smith 1 Sept.

Smith 3 Sept.

Chorley 23 July

Chorley 28 July 